\title{
,

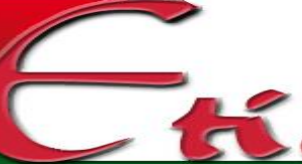 \\ EVALUACIÓN DE LA CALIDAD EN SERVICIOS DE EDUCACIÓN SUPERIOR A DISTANCIA: ESCALA SERVQUAL Y ANÁLISIS FACTORIAL
}

A quality evaluation in higher distance education services: servqual scale and factorial analysis

Miguel Ángel Tobías Martínez migueltobias@ufpr.br https://orcid.org/0000-0001-9832-4940 Universidade Federal do Paraná (Brasil)

\author{
Juan Antonio Fuentes Esparrell \\ fuentese@ugr.es \\ https://orcid.org/0000-0003-4821-7092 \\ Universidad de Granada (España) \\ Isabel Feriche Rodríguez \\ isabelferiche@gmail.com \\ https://orcid.org/0000-0003-3158-5091
}

Francisco José Álvarez Jiménez colesanmiguel@gmail.com https://orcid.org/0000-0003-1500-8657 CEIP San Miguel Almuñecar (España)

Recibido: 02/06/2020

Evaluado: $10 / 07 / 2020$

Revisado: 03/09/2020

Aceptado: 30/09/2020

\section{Resumen}

La sociedad, los negocios y la tecnología cambian rápidamente, es por eso que la percepción del aprendizaje tiene que ser cambiada para poder mantener el ritmo frente al ambiente competitivo. En la actualidad ha habido un cambio 


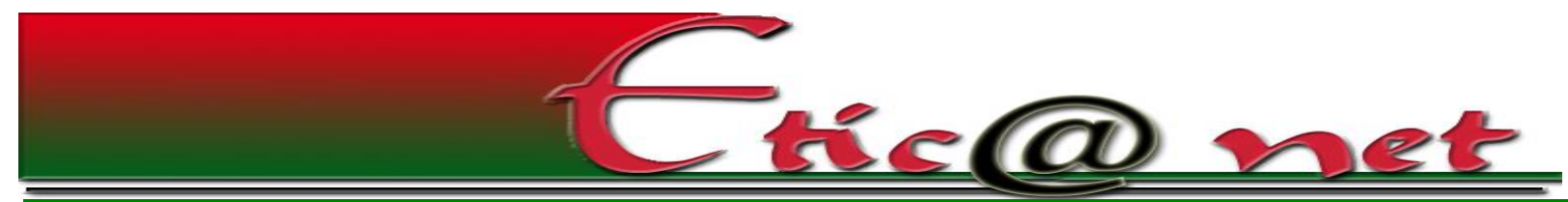

Revista científica electrónica de Educación y Comunicación en la Sociedad del Conocimiento Publicación en línea (Semestral) Granada (España) Época II Vol. 20 (2) Julio-Diciembre de 2020 ISSN: 1695-324X

significativo en la enseñanza superior y en el proceso de aprendizaje en general, con el auxilio de las tecnologías de la información y comunicación (TIC) y, especialmente, debido a Internet. En este contexto se destaca la EaD (Educación a Distancia). Esta a su vez ha presentado expansión en el mercado y también comodidad al alumno, pues él escoge el horario y dónde quiere estudiar. Esta investigación tiene el objetivo de evaluar la calidad (a través de la escala SERVQUAL y del modelo gap) de la EaD en una institución ubicada en Rio Grande do Sul. También la investigación se propone refinar (validar) un instrumento de investigación, para perfeccionarlo, utilizando el análisis factorial. Los resultados apuntaron que en la institución analizada existen gaps (vacíos) a ser llenados. Y el análisis factorial se mostró útil para el refinamiento del instrumento de investigación. Pues, eso hizo que hubiera mayor homogeneidad entre las variables de cada dimensión. Por lo tanto, la investigación se muestra útil tanto a nivel académico como empresarial.

\section{Abstract}

Society, business and technology change rapidly, that is why the perception of learning has to be changed in order to keep up with the competitive environment. At present there has been a significant change in higher education and in the learning process in general, with the help of information and communication technologies (ICT) and, especially, due to the Internet. In this context it is highlighted the EAD (Distance Education). This in turn has presented expansion in the market and also convenience to the student, because he chooses the time and where he wants to study. This research has the objective of evaluating the quality (through the scale SERVQUAL and the gap model) of the EaD in an institution located in Rio Grande do Sul. Also the research proposes to refine a research instrument, to make it more accurate, using the factorial analysis. The results pointed out that in the analyzed Institution there are gaps (gaps) to be filled. And the factorial analysis proved useful for the refinement of the research instrument. This made it possible to have greater homogeneity among the variables of each dimension. Therefore, the research proves useful both at the academic and business level. 


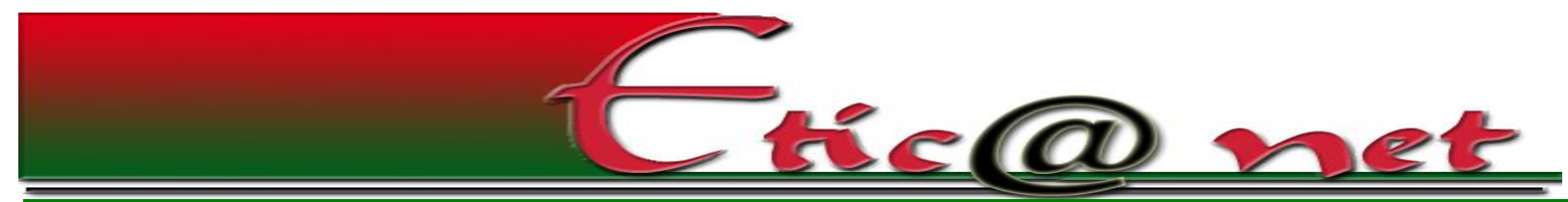

Revista científica electrónica de Educación y Comunicación en la Sociedad del Conocimiento Publicación en línea (Semestral) Granada (España) Época II Vol. 20 (2) Julio-Diciembre de 2020 ISSN: 1695-324X

Palabras Clave: Educación a distancia; e-learning; servicios de calidad; escala SERVQUAL; TIC.

Keywords: Distance education; e-learning; quality services; SERVQUAL scale; ICT.

\section{Introducción}

El rápido desarrollo tecnológico ha cambiado el mundo en todos los aspectos, incluyendo la enseñanza a distancia o EaD (Educación o Enseñanza a Distancia). La propia tecnología muestra cómo EaD está cambiando el tradicional modelo de aprendizaje. De esta forma la educación a EaD (Almeida, 2003), como modalidad educativa alternativa para transmitir informaciones e instrucciones a los alumnos a través del correo y recibir de estas respuestas a las lecciones propuestas, hizo que la educación convencional accesible a las personas residentes en áreas aisladas o a aquellos que no tenían condiciones de cursar la enseñanza regular en el período apropiado.

La EaD permite al estudiante compatibilizar su curso con sus posibilidades de tiempo, realizarlo en el ritmo deseado y en cualquier lugar disponible (Capeletti, 2014). El contenido puede ser ofrecido por el profesor en forma de texto o video-aula y la interacción con colegas y profesor es realizada por foros, chats, blogs (diarios en línea en que se publican contenidos con espacio para comentarios del lector), entre otros.

También en el medio organizacional surgieron herramientas que son soportadas por las TIC (Tecnologías de la Información y Comunicación) utilizadas en entrenamientos. En la llamada economía del conocimiento es fundamental la promoción del aprendizaje para obtener y retener el conocimiento en los colaboradores. El e-learning es una de las herramientas que ayuda a las empresas a través de la capacitación al desarrollo e introducción de nuevos productos, mejoramiento y flujo de información, obtención de un mayor compromiso con los empleados y fomentar la creatividad. 


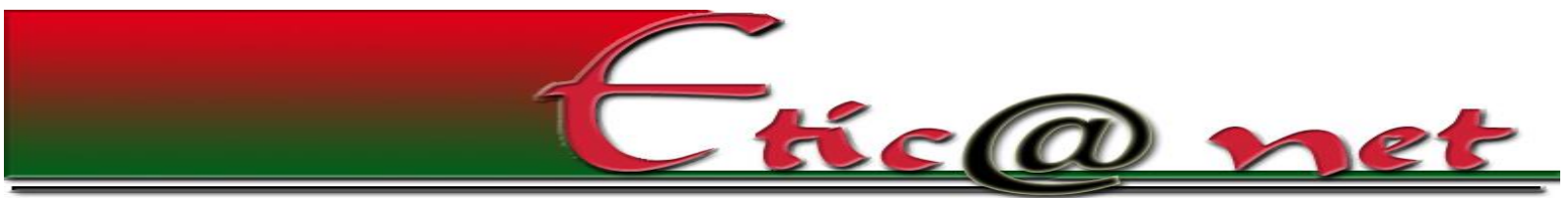

Revista científica electrónica de Educación y Comunicación en la Sociedad del Conocimiento Publicación en línea (Semestral) Granada (España) Época II Vol. 20 (2) Julio-Diciembre de 2020 ISSN: 1695-324X

En este contexto, el presente estudio tiene el objetivo de evaluar la calidad de la Enseñanza a Distancia - EAD, por medio del uso de la escala SERVQUAL y también refinar (validar) un instrumento de evaluación de la calidad del EaD por medio de las técnicas de análisis factorial. También propone identificar qué criterios de las dimensiones de la calidad que superan o no las expectativas de los alumnos. Se justifica la importancia de esta investigación por el hecho de que la EaD se está volviendo cada vez más competitiva en el mercado y eso requiere tener una gestión cualificada. Y la evaluación de la calidad puede ser muy útil en este caso. En el ámbito académico, se justifica por el hecho de proponer el refinamiento de un instrumento de investigación para evaluar la calidad del EaD y así servir para investigaciones futuras.

\section{Marco Teórico}

Este apartado trata sobre la definición y/o conceptualización de los siguientes temas: desambiguaciones entre EaD (Educación a Distancia), Educación en línea y el E-learning; EaD y el e-learning: conceptos e implicaciones; calidad de los servicios prestados; análisis factorial; escala SERVQUAL.

Desambiguación entre EAD (educación a distancia), educación en línea y el e-learning

Para facilitar la comprensión de la presente investigación, es importante discutir sobre el origen de esos conceptos que pueden tender a ser confundidos. La $\mathrm{EaD}$ tiene una larga crónica de ensayos, éxitos y fracasos. En cuanto a su aparición se puede hablar de las cartas de Platón y de las epístolas de San Pablo. Esto dirige a las primeras experiencias de educación por correspondencia iniciadas a finales del siglo XVIII.

Posteriormente ocurre un desarrollo a mediados del siglo XIX hasta llegar a los días actuales.

En la actualidad, se utilizan diversos recursos multimedios (Park et al., 2011, Rinaldi, 2014) que van desde los impresos hasta simuladores online (Tobías y 


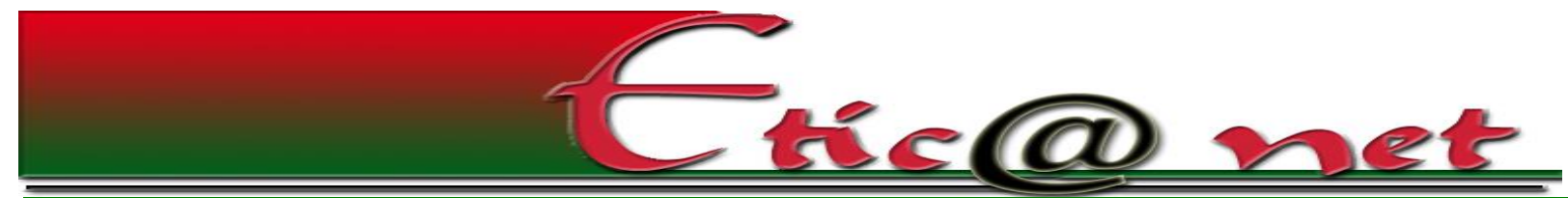

Revista científica electrónica de Educación y Comunicación en la Sociedad del Conocimiento Publicación en línea (Semestral) Granada (España) Época II Vol. 20 (2) Julio-Diciembre de 2020 ISSN: 1695-324X

Fuentes, 2019; Tobías, Fuentes, Duarte y Luiz, 2016; González, Quintero, Mendigutxia-Sorabilla, Reche y Fuentes, 2020). Esto ayuda a las TIC, que proporcionan la comunicación instantánea mediante diversos recursos tecnológicos permitiendo de esta forma la aplicación de interacción entre el estudiantado y el profesorado (Pareja, Fernández y Fuentes, 2019). Y así se utiliza de la Inteligencia Artificial (Cantu-Ortiz, 2014) como medio para satisfacer las necesidades para cumplir las competencias que se necesitan de un profesional en este siglo XXI.

La educación en línea, la educación a distancia, el e-learning son términos usuales del área de la educación, pero no son congruentes entre sí. Es decir, se tiene la conceptualización de la siguiente forma (Almeida, 2003):

- La educación online es una modalidad a distancia realizada vía Internet, cuya comunicación ocurre de forma sincrónica (simultánea) o asincrónica (no simultánea). Tanto puede utilizar Internet para distribuir rápidamente la información como puede hacer uso de la interactividad propiciada por ésta.

- La Educación a Distancia $(\mathrm{EaD})$ puede realizarse por el uso de diferentes medios (correspondencia postal o electrónica, radio, televisión, teléfono, fax, computadora, Internet, etc.), técnicas que posibiliten la comunicación y abordajes educativos; se basa tanto en la noción de distancia física entre el alumno y el profesor como en la flexibilidad del tiempo y en la ubicación del alumno en cualquier espacio.

- El e-learning (Gallego, 1996) es una modalidad de Educación a Distancia (Seattler, 2004) con soporte en Internet que se desarrolló a partir de necesidades de empresas relacionadas con el entrenamiento de sus empleados. Cuyas prácticas están centradas en la selección, organización y disponibilidad de recursos didácticos hipermediáticos.

Por lo tanto, para la sociedad del siglo XXI la Educación a distancia, la Educación en línea y el E-learning, junto con la apertura y la diversidad de las culturas, se convierte en un gran avance y un diferencial en la tecnología educativa (Mirelles, Fuentes y Ortega, 2018). 


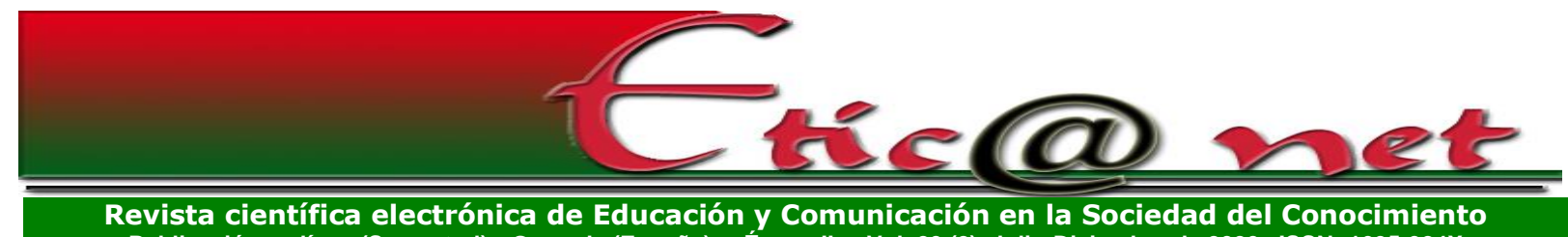

Revista científica electrónica de Educación y Comunicación en la Sociedad del Conocimiento Publicación en línea (Semestral) Granada (España) Época II Vol. 20 (2) Julio-Diciembre de 2020 ISSN: 1695-324X

\section{EAD y el E-learning: conceptos e implicaciones}

En la actual economía del conocimiento lo fundamental es cómo las empresas promueven el aprendizaje, obtienen y retienen el conocimiento de sus colaboradores. Wang et al. (2007), haciendo referencia sobre los avances de Internet, aumento de recursos de computación y dispositivos móviles, prevalencia de contenidos multimedia, todo ello seguido por cambios sociales, tecnológicos y culturales. Y, ha impactado en las tecnologías de la información y comunicación (TIC) haciendo evolucionar, de esta forma, para interacciones sociales en general. En este contexto se destaca la EaD.

La EaD comenzó a avanzar a pasos agigantados en Brasil y ya responde por expresivo número de cursos ofrecidos (Tobías, Fuentes, Duarte y Luiz, 2016). Las evaluaciones de pruebas y concursos demuestran que ya se cuenta entre los mejores clasificados la presencia de candidatos que sólo realizaron cursos a distancia (Souza, 2009, Patto, 2013). Y eso es la demostración de la conocida era del conocimiento.

Pero el concepto de EaD no es reciente. Su concepto es bastante antiguo y remonta la antigüedad, específicamente, en las cartas de Platón enviadas a sus discípulos conteniendo seguimientos de sus pensamientos filosóficos (Schuelter, 2005; Capeletti, 2014). Como una forma de firmar sus convicciones, se entiende que la intención es proporcionar a sus discípulos enseñanzas.

La enseñanza a distancia requiere disciplina y autonomía del alumno (Amarilla Filho, 2011, Thoms y Eryilmazem, 2014), pues depende de un estudio solitario por la falta de socialización con los colegas, la ausencia física del profesor y también las dificultades en comprender las herramientas disponibles en el entorno virtual (Fuentes, 2011).

Las clases a distancia se desarrollan en el entorno virtual de aprendizaje (EVA), que son sitios o plataformas virtuales que tienen interfaces de comunicación e información para la mediación de la enseñanza y el aprendizaje (Tobías y Fuentes, 2019 y Pareja, Fuentes, Fernández y Hernandez, 2017). La elección del EVA depende de la propuesta pedagógica 


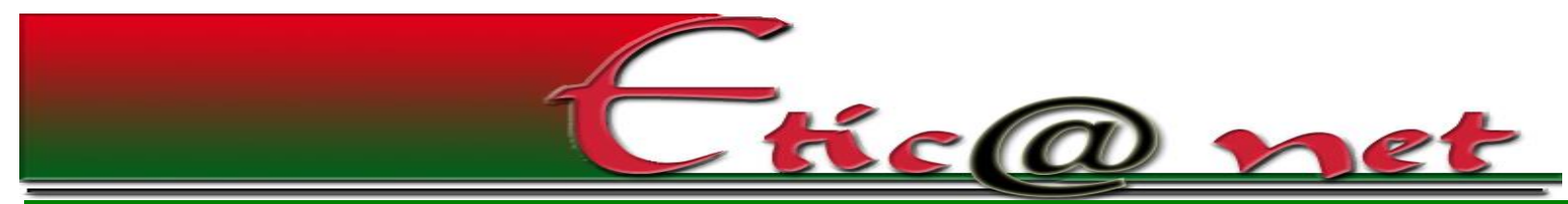

Revista científica electrónica de Educación y Comunicación en la Sociedad del Conocimiento Publicación en línea (Semestral) Granada (España) Época II Vol. 20 (2) Julio-Diciembre de 2020 ISSN: 1695-324X

del curso ofrecido (Capeletti, 2014). El EVA basado en Moodle (Sabbatini, 2014) posee todas las herramientas que los profesores de contenidos necesitan para construir el ambiente en línea. Primero, estos profesores son entrenados en la filosofía pedagógica y en el uso eficiente, rápido y de calidad de los recursos disponibles en Moodle.

Por lo tanto, se puede definir la EaD como un conjunto de métodos de aprendizaje utilizados para enseñar a los alumnos que están geográficamente separados de la institución de enseñanza, de los profesores y de los otros alumnos. $Y$, de esta forma se aplica una colección de métodos para crear un ambiente propicio para el aprendizaje. Esta forma de aprendizaje ofrece muchas ventajas en relación al aprendizaje tradicional, tales como, proporcionar a los individuos la capacidad de aprender a su propio ritmo y en su propio espacio.

Pero cuando se habla de EaD otro término no puede ser olvidado, debido a su importancia en la actualidad que es el e-learning. En realidad, es una modalidad del EaD, pero orientada hacia el contexto organizacional. Él es una manera revolucionaria para capacitar a la fuerza de trabajo con las habilidades y conocimientos necesarios para transformar los cambios en ventajas. El elearning (Almeida, 2003, Ooi, 2014) tuvo sus orígenes en el entrenamiento corporativo. Según la perspectiva de entrenamiento comienza a incorporar prácticas orientadas al desarrollo de competencias a través de la interacción y colaboración entre los aprendices.

En la actualidad, la solución para superar las dificultades de tiempo, desplazamiento y espacio físico que conlleva a muchas personas reunidas, el e-learning está siendo señalado como la tendencia actual de entrenamiento, aprendizaje y formación continuada en el sector empresarial (Almeida, 2013).

Muchas empresas están descubriendo que el e-learning tiene prácticamente los mismos atributos como procesos básicos de gestión del conocimiento y, por lo tanto, puede ser utilizado como una herramienta para GC (Wild, Griggs y Downing, 2002, Tseng, 2014). El aprendizaje electrónico puede definirse como contenido instruccional o técnicas de aprendizaje (Swart y Kinnie, 2007, Liyanage et al., 2009, Hakala, 2011, Stefano y Casarotto, 2013, Floyde, 2013, 


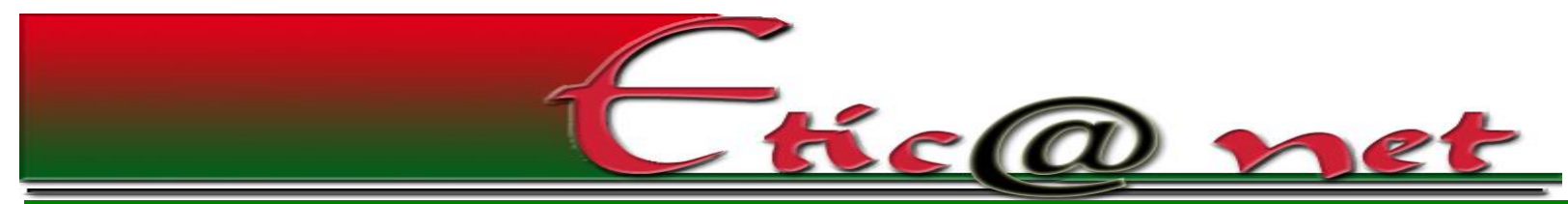

Revista científica electrónica de Educación y Comunicación en la Sociedad del Conocimiento Publicación en línea (Semestral) Granada (España) Época II Vol. 20 (2) Julio-Diciembre de 2020 ISSN: 1695-324X

Wang, 2014, Shang et al., 2014) facilitada por la tecnología electrónica, que quedan a disposición por medio de repositorios, por ejemplo, de los funcionarios, para que éstos puedan utilizarlos cuando sientan necesidad. $\mathrm{O}$ el e-learning es el uso de tecnologías de Internet para crear un entorno de aprendizaje, que incluye una gran variedad de instrucciones e información de recursos y soluciones para proporcionar este ambiente.

Por lo tanto, se puede afirmar que el objetivo del e-learning es mejorar el desempeño individual y organizacional (Yilmaz, 2012, Fryer, Bovee y Nakao, 2014). El objetivo es aumentar los conocimientos, habilidades y capacidades productivas de los individuos en una situación global. El e-learning es importante no sólo por razones económicas, pero tiene importantes beneficios sociales (Guha y Maji, 2008, Kakoty, Lal y Sarma, 2011). Al ampliar el acceso a la educación y oportunidades de formación para los diversos segmentos de la sociedad (Martínez, Chávez y Fuentes, 2013); tiene un potencial para reducir las disparidades económicas causadas por la negación de la educación para el sector económicamente desfavorecido de la población ofreciéndoles mejores oportunidades de trabajo y crecimiento de la renta en todos los niveles.

Organizaciones que adoptan la noción del conocimiento como un recurso que crean valor cuando se comparte. Por ejemplo, el entrenamiento en los días de hoy ya no es visto como una extravagancia sino como una necesidad con la finalidad de crear ventajas competitivas sostenibles frente a los competidores. Esto hace el entrenamiento más prometedor para el e-learning.

El e-learning se presenta como una herramienta atractiva para las empresas por varios factores, tales como: reducción de costos, acceso global a los cursos, fácil distribución de materiales de aprendizaje corporativo, flexibilidad en el horario de los empleados para programar sus cursos...

Por lo tanto, el e-learning es el intercambio de conocimiento a través de los medios en línea y, para ser eficaz el e-learning no debe ser sólo una manera pasiva de entregar el aprendizaje. En caso contrario, la organización puede convertirse en un montón de información, hasta el punto de que los colaboradores quedan tan asustados por su volumen que no pueden separar lo útil de lo inútil. Si se aplica y explora correctamente, puede ser un beneficio 


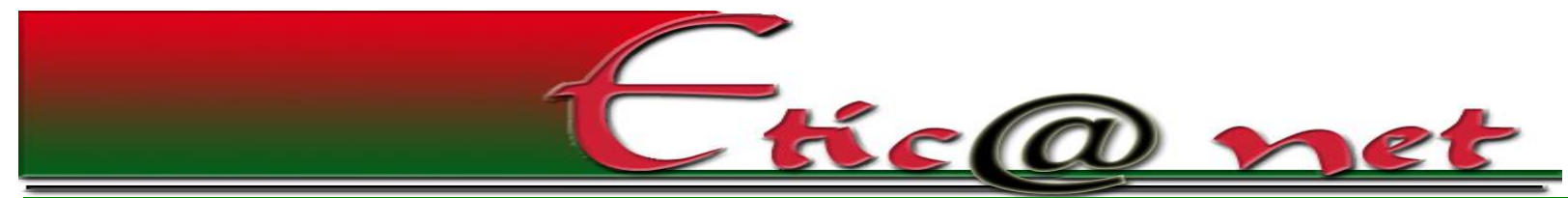

Revista científica electrónica de Educación y Comunicación en la Sociedad del Conocimiento Publicación en línea (Semestral) Granada (España) Época II Vol. 20 (2) Julio-Diciembre de 2020 ISSN: 1695-324X

para las organizaciones y sus stakeholders, proporcionando acceso tanto al conocimiento explícito, así como al conocimiento tácito.

\section{Calidad en los servicios ofrecidos}

De acuerdo con la Real Academia Española - RAE (2019) -, la excelencia del latín excellentia, es una calidad superior o bondad que hace de singular apreciación, es también un tratamiento de respeto y cortesía a quien va dirigido sea por su dignidad o categoría. Con respecto al área empresarial u organizacional, en la actualidad es imprescindible el uso de la excelencia para satisfacer tres factores importantes en la creación de productos o servicios que son: calidad, seguridad y responsabilidad por el medio ambiente.

Así, una de las definiciones más encontradas en la literatura es la que describe la calidad en servicios como la capacidad de satisfacer las necesidades de los clientes. La evaluación de la calidad percibida (Snoj, Korda y Mumel, 2004, Hamer, 2006, Moliner, 2009, Edward y Sahadev, 2011, Das, 2014) es realizada por el cliente durante o después del proceso de prestación del servicio; y se da por medio de la comparación de la calidad experimentada o percibida y la esperada por el cliente. La calidad percibida es una evaluación global del servicio relacionada con la superioridad del servicio, mientras que la satisfacción está relacionada con una transacción específica. Es decir, la calidad en un determinado momento o etapa del servicio. De este modo, el proceso de evaluación de la calidad del servicio se da en función de sus expectativas (calidad esperada) y de su percepción del servicio (calidad experimentada).

La prestación del servicio es el principal responsable de la percepción del cliente. Durante el proceso de prestación de servicio se produce un "encuentro de servicio". En el caso de que se produzca un cambio en la calidad de un servicio, el encuentro se combinará con diversos momentos de la verdad (Löfgren, 2005, Löfgren, Witell y Gustafsson, 2008, Klaus y Maklan, 2012). Los momentos de la verdad son verdaderas oportunidades para que el proveedor de servicio compruebe para el cliente la calidad de sus servicios. Es decir, es cuando el cliente ve el servicio sucediendo. 


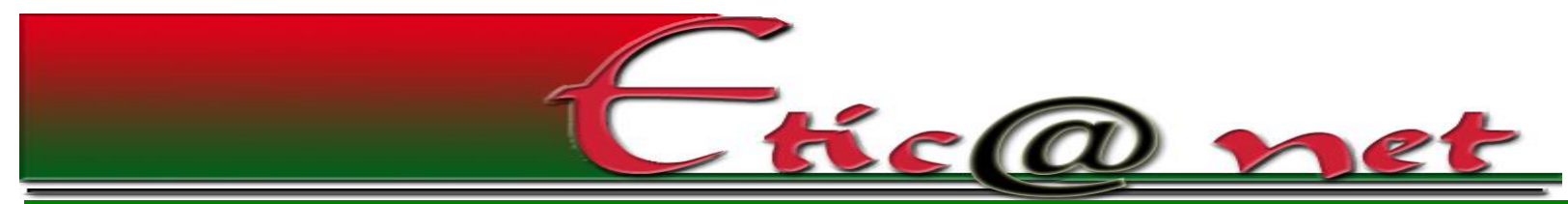

Revista científica electrónica de Educación y Comunicación en la Sociedad del Conocimiento Publicación en línea (Semestral) Granada (España) Época II Vol. 20 (2) Julio-Diciembre de 2020 ISSN: 1695-324X

Klaus y Maklan (2012) enfatizan la importancia de la recuperación del servicio y la flexibilidad de lidiar con los clientes (ya que pueden surgir complicaciones en el proceso de adquisición de un servicio) en los momentos de la verdad. También, en este momento el cliente evalúa las habilidades interpersonales del proveedor de servicios en el manejo de situaciones inesperadas.

La calidad de los servicios prestados es uno de los principales factores de competitividad y es el punto crucial de la relación cliente/organización. Para la garantía de la continuidad de los negocios es importante que ocurra una aproximación de esa relación. Y, esto puede ser alcanzado, principalmente, por medio del foco en el cliente y por la calidad de la atención.

Por lo tanto, para cada tipo de servicio puede existir un conjunto específico de determinantes de la calidad. En el presente trabajo se analizan los resultados de la evaluación de la calidad de los elementos, que se encuentran en la literatura (Parasuraman, Zeithaml y Berry, 1985, 1988; Ghobadian, Speller y Jones, 1994; Johnston, 1995, 2005; Parasuraman, 2004; Kokkinis, Mihiotis y Pappis, 2006); y en el caso de que se produzca un cambio en la calidad de la información, actitudes y comportamiento; acceso y flexibilidad; confiabilidad y honestidad; recuperación; reputación y credibilidad; la comunicación; costes, etc.

Así, cada tipo de servicio puede tener determinantes que se consideran críticos para el sector en que se encuentra. De la misma forma, cada momento de la verdad en los diversos tipos de servicios sufrirá un mayor o menor impacto de los diferentes determinantes de la calidad. La percepción de la calidad y la posterior evaluación del servicio se dan en relación a los determinantes considerados más importantes para el cliente en cada momento de la verdad.

\section{Análisis factorial}

El análisis factorial (Carús, 2014) busca identificar un conjunto menor de variables hipotéticas (factores), con el objetivo de reducir la dimensión de los datos y posibilita su agrupación en factores, de acuerdo con su comportamiento, sin pérdida de información (Hair et al., 2006). Se parte de la estructura de dependencia existente entre las variables de interés (en general 


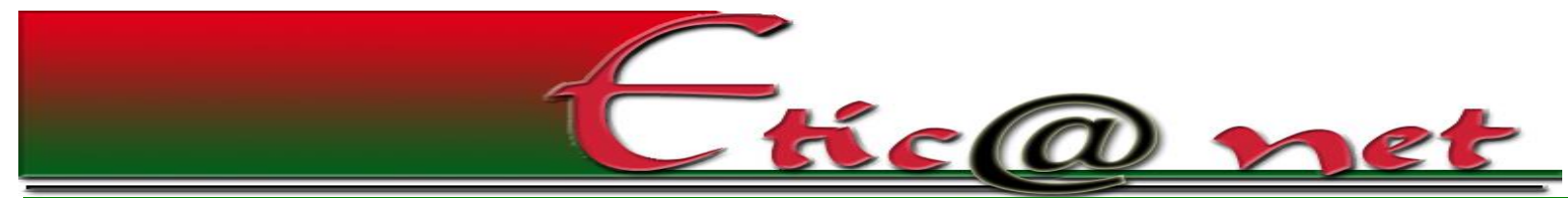

Revista científica electrónica de Educación y Comunicación en la Sociedad del Conocimiento Publicación en línea (Semestral) Granada (España) Época II Vol. 20 (2) Julio-Diciembre de 2020 ISSN: 1695-324X

representada por las correlaciones o covariancias entre ellas), permitiendo la creación de un conjunto menor (variables latentes, o factores) obtenidas como función de las variables originales. Es posible, también, saber cuánto cada factor está asociado a cada variable y cuánto el conjunto de factores explica la variabilidad general de los datos originales.

Este tipo de análisis (Lasch y Janker, 2005, Diana, 2014) es frecuente, cuando se está interesado en el comportamiento, de una variable o grupos de variables en covarianza con otras. El análisis factorial es una técnica de análisis multivariada que tiene como objetivo examinar la interdependencia entre variables y su principal característica es la capacidad de reducción de datos.

La extracción de los factores puede ser realizada por medio del modelo de Análisis de Componentes Principales (ACP) (Öcal et al.; 22). Este es un método estadístico (Hair et al., 2006, González-Aguilera et al., 2013) multivariado que permite transformar un conjunto de variables iniciales correlacionadas entre sí, en otro conjunto de variables no correlacionadas (ortogonal), las llamadas componentes principales, que resultan de combinaciones lineales del conjunto inicial. Realizada la solución factorial deben ser examinadas todas las variables destacadas en cada factor y nombrar un "rótulo" que mejor lo represente. Las variables con mayor carga factorial (Noguera, 2014) son consideradas de mayor importancia y deben influir más en el "rótulo" del factor.

\section{Escala SERVQUAL}

En el campo de la evaluación de la calidad de los servicios, los trabajos de Parasuraman, Berry y Zeithaml se conocen bastante. En 1985, estos autores publicaron un modelo conceptual de calidad basado en cinco Gaps (o vacíos), que fue ampliamente difundido. En la Figura 1 se presenta este modelo de calidad en servicios. 


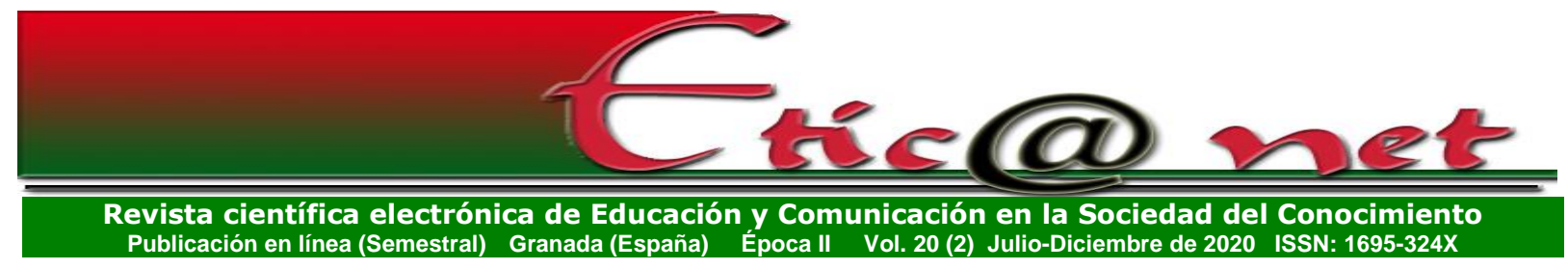

Figura 1 - Modelo de calidad de los servicios de Parasuraman; Berry y Zeithaml

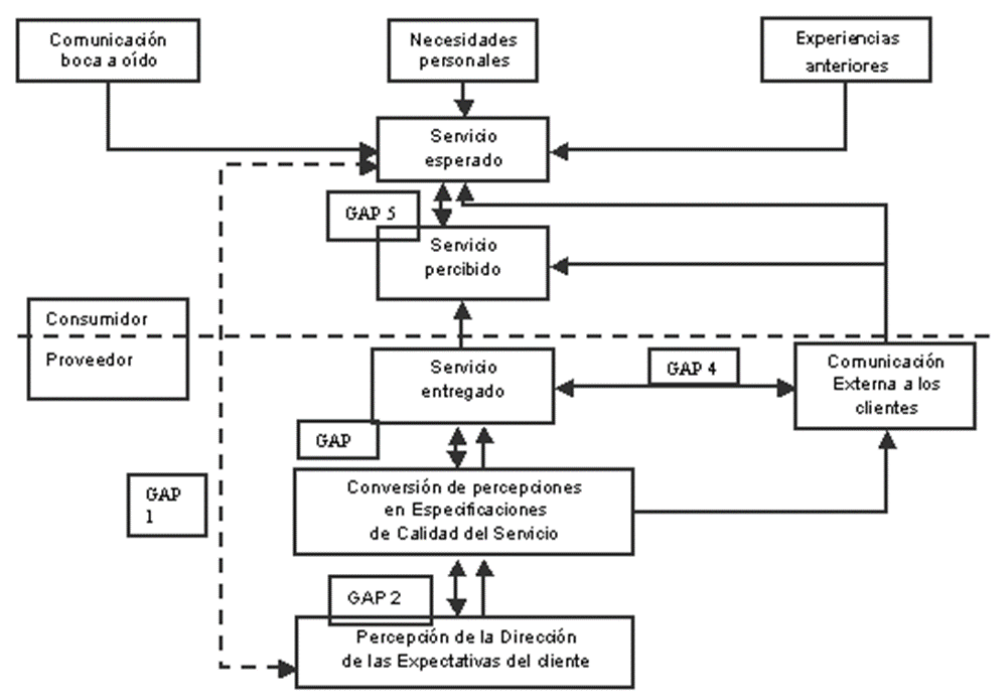

Fuente: Parasuraman, Berry y Zeithaml (1985, p.44).

El cuadro 1 muestra las situaciones a las que indican los GAP.

\section{Cuadro 1 - Modelo de los GAP}

\begin{tabular}{|c|l|}
\hline Gap & \multicolumn{1}{|c|}{ Situación } \\
\hline Gap 1 & $\begin{array}{l}\text { Brecha entre las expectativas del consumidor - Gestión de la percepción - se refiere a las } \\
\text { discrepancias que puedan existir entre las percepciones de los ejecutivos y las expectativas } \\
\text { reales de los consumidores. }\end{array}$ \\
\hline Gap 2 & $\begin{array}{l}\text { Brecha entre la percepción de gestión - especificaciones de calidad de servicio - los } \\
\text { gerentes no pueden incluir especificaciones de calidad de servicio, todos los elementos } \\
\text { capaces de satisfacer las expectativas del cliente, no traducir correctamente sus } \\
\text { expectativas. }\end{array}$ \\
\hline Gap 3 & $\begin{array}{l}\text { Brecha entre especificaciones de la calidad del servicio - prestación del servicio - la } \\
\text { especificación del servicio puede ser adecuada, pero el personal de ejecución puede } \\
\text { cometer errores, y por lo tanto influir en la calidad final. }\end{array}$ \\
\hline Gap 4 & $\begin{array}{l}\text { Brecha entre la prestación de servicios - la comunicación extema con el consumidor - es la } \\
\text { brecha entre el servicio prometido, a través de la publicidad y otras formas de } \\
\text { comunicación. }\end{array}$ \\
\hline Gap 5 & $\begin{array}{l}\text { Brecha entre el servicio esperado y el servicio percibida - esta brecha es el resultado de los } \\
\text { otros cuatro lagunas, que se producen sólo si uno o más de los anteriomente descritos. }\end{array}$ \\
\hline
\end{tabular}

Fuente: Adaptado de Parasuraman, Berry y Zeithaml (1985, p.45).

Algunos años después los autores (Parasuraman et al., 1988) propusieron un instrumento para medir la calidad de los servicios - la Escala SERVQUAL. Esta escala fue desarrollada por Parasuraman et al. (1988), para evaluar la calidad 


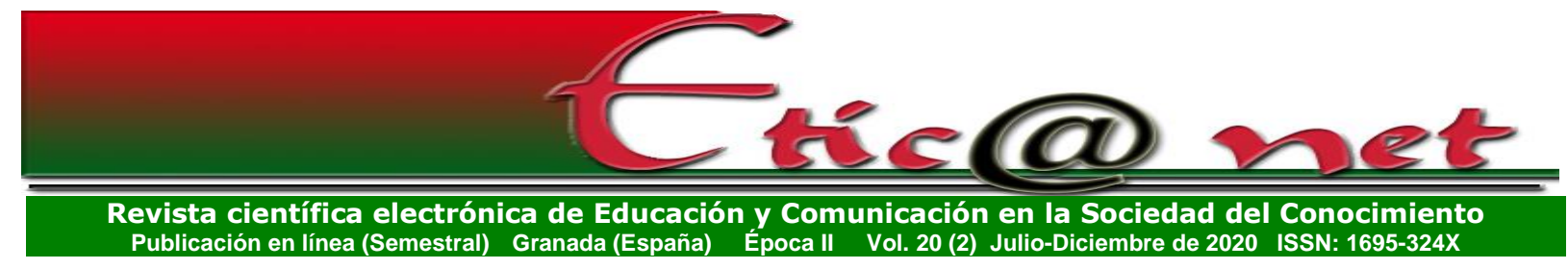

percibida por los clientes por medio de la medición del Gap 5 del modelo de calidad en servicios (fallas o gaps), anteriormente desarrollado por este autor (Parasuraman et al., 1985).

Inicialmente ese instrumento fue basado en diez dimensiones, sean ellas: Tangibles; fiabilidad; Capacidad de respuesta; la comunicación; credibilidad; la seguridad; competencia; cortesía; Comprender/conocer a los clientes; el acceso. Posteriormente, por medio del análisis factorial, estas diez dimensiones se redujeron en cinco dimensiones genéricas de calidad de servicio, como muestra la Figura 2.

Figura 2 - Escala SERVQUAL

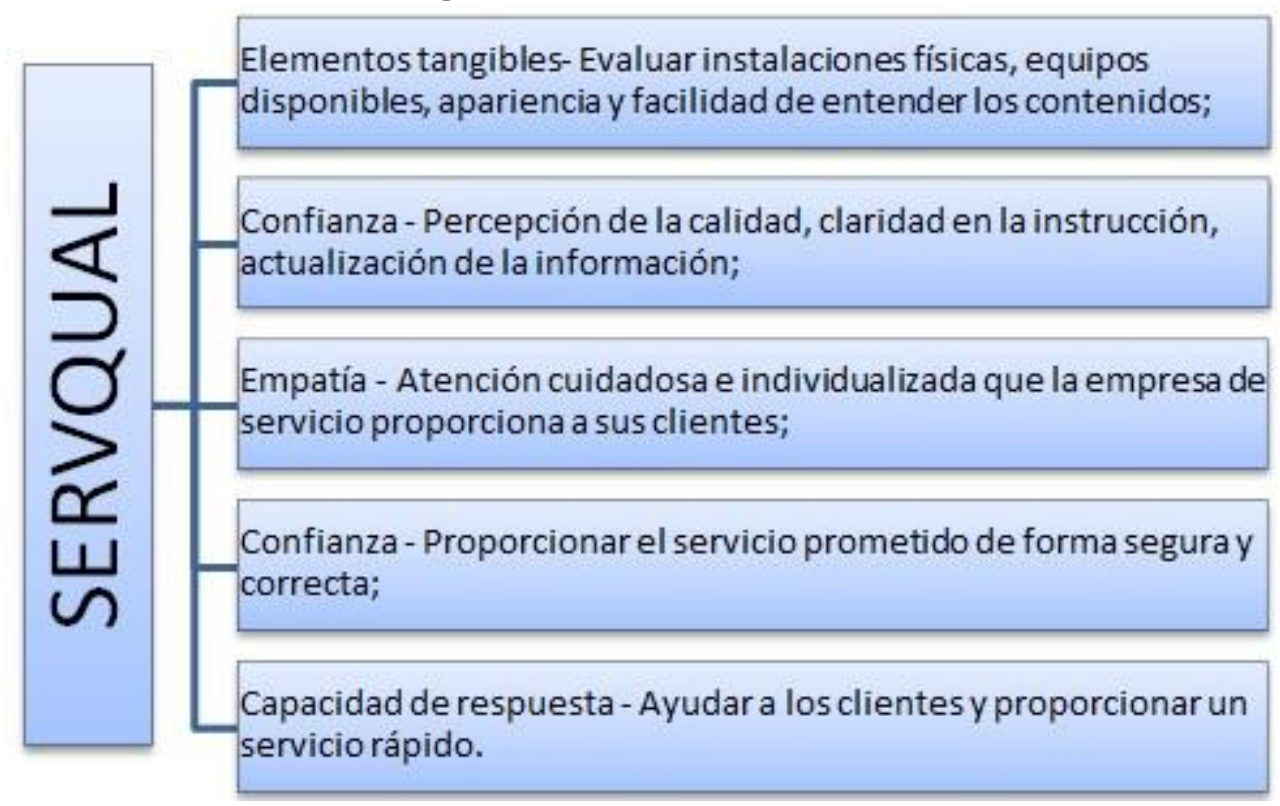

Fuente: Elaborado por los autores a partir de Parasuraman, Berry y Zeithaml (1988, p. 23).

La escala SERVQUAL se destina para la evaluación de los ítems de expectativas y percepciones, se utiliza la escala Likert de 5 ó 7 puntos. Para validar esta herramienta Parasuraman et al. (1988), aplicaron en cuatro ramas de servicios diferentes: bancos, tarjetas de crédito, servicios de reparación y servicios de telefonía de larga distancia. Este estudio utilizará una adaptación de la escala SERVQUAL como instrumento para la obtención de informaciones referentes a la calidad del EaD. 


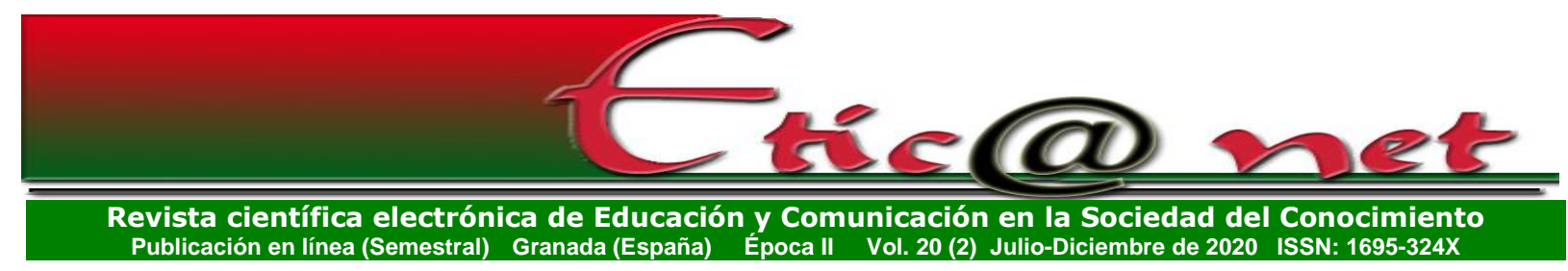

Cuadro 2 - Ejemplos de estudios utilizando la escala SERVQUAL

\begin{tabular}{|c|c|c|}
\hline Autor(es) & $\begin{array}{l}\text { Evaluación de la } \\
\text { Calidad }\end{array}$ & Dimensiones utilizadas \\
\hline $\begin{array}{l}\text { Cook y } \\
\text { Thompson } \\
(2000)\end{array}$ & Librerias & $\begin{array}{c}\text { Tangibles; la confianza; la capacidad de respuesta; la garantia; } \\
\text { Empatia. }\end{array}$ \\
\hline $\begin{array}{c}\text { Kange } \\
\text { Bradley (2002) }\end{array}$ & $\begin{array}{l}\text { Servicios de TI } \\
\text { (tecnología de la } \\
\text { Información) }\end{array}$ & Personas habilitadas; Atributos. \\
\hline $\begin{array}{l}\text { Van Iwaarden } \\
\text { et al. (2004) }\end{array}$ & E-semmercs. & $\begin{array}{l}\text { Claridad de propósito; diseño; la comunicación; fiabilidad; Servicio } \\
\text { y las preguntas más frecuentes; Accesibilidad y velocidad; Elección } \\
\text { de productos o servicios; Confirmación de la solicitud; Compra del } \\
\text { producto; Reconocimiento del usuario; Servicios a dicionales; } \\
\text { Incentivos para el comprador. }\end{array}$ \\
\hline Alkbaba (2006) & $\begin{array}{l}\text { Servicios de } \\
\text { Hotelería }\end{array}$ & $\begin{array}{l}\text { tangibles; Adecuación en la prestación del servicio; comprensión y } \\
\text { cuidado; la garantía; Conveniencia. }\end{array}$ \\
\hline $\begin{array}{l}\text { Grigoroudis et } \\
\text { al. (2008) }\end{array}$ & Web Sites. & $\begin{array}{l}\text { Relevancia; utilidad; fiabilidad; conocimientos especializados; } \\
\text { arquitectura; navegabilidad; eficiencia; diseño; Animación. }\end{array}$ \\
\hline $\begin{array}{l}\text { Ude, Bagchi y } \\
\text { Kirs (2010) }\end{array}$ & E-semmercs & $\begin{array}{c}\text { Percepción de riesgo; Conveniencia del servicio; Contenido del } \\
\text { Sitio; Calidad del servicio web; Satisfacción del cliente; Intenciones } \\
\text { de compra. }\end{array}$ \\
\hline $\begin{array}{l}\text { Charles y } \\
\text { Kumar (2014) }\end{array}$ & $\begin{array}{l}\text { Servicios } \\
\text { Bancarios }\end{array}$ & Tangibles; la confianza; habilidades; Conveniencia. \\
\hline
\end{tabular}

Fuente: Elaborado por los autores.

La escala SERVQUAL se utiliza como una técnica de diagnóstico para identificar, en varios tipos de servicios, los puntos fuertes y débiles de la empresa, sirviendo de base para la mejora continua. También puede ser utilizada para diversas aplicaciones, entre ellas la identificación de tendencias de la calidad de los servicios cuando se aplica periódicamente con los clientes. Otra aplicación es en el área de marketing para comparar un servicio a los de sus competidores, identificando cuáles dimensiones de la calidad son superiores a los de los competidores y cuáles necesitan ser mejorados.

\section{Procedimientos Metodológicos}

La presente investigación es de naturaleza descriptiva y tiene como base la investigación cuantitativa. La recolección de datos fue realizada por medio de la aplicación de cuestionario (Stefano, 2013). En esta investigación se utilizó una adaptada a la escala SERVQUAL. Y así, pasó a basarse en las siguientes 


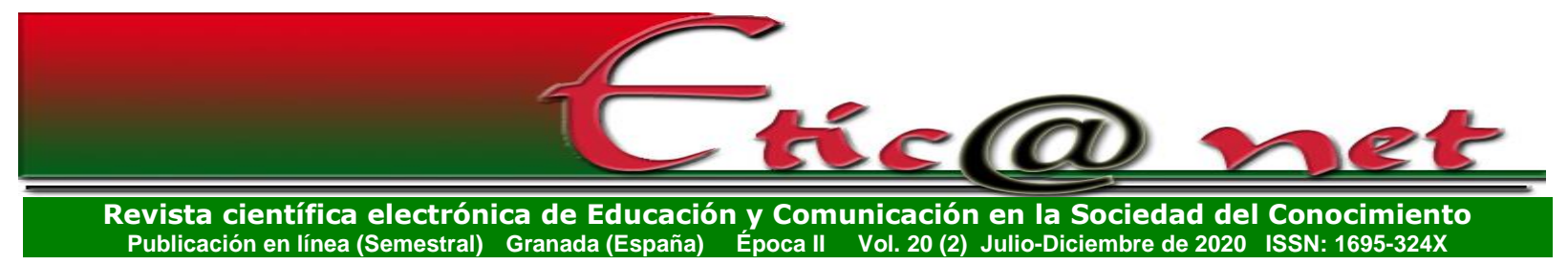

dimensiones de la calidad: Dimensión Plataforma Moodle, profesor, tutor, infraestructura del Polo Presencial y Material Didáctico (Cuadro 3).

Cuadro 3 - Dimensiones de la calidad utilizadas en la investigación

\begin{tabular}{|l|l|}
\hline Descripción de la variable & \multicolumn{1}{|c|}{ Sigla } \\
\hline Dimensión Plataforma Moodle & DMT \\
\hline Uso de las funciones de audio. & RADU \\
\hline Uso de las funciones de vídeo. & RIVD \\
\hline Uso de los recursos de animación. & RNA \\
\hline Actualización de la plataforma Moodle. & ATPP \\
\hline Acceso a archivos en cualquier formato (PDF, DOC, PPT, etc.) o enlaces externos (URL). & AARF \\
\hline Plataforma funcional, instructiva y clara. & PLICF \\
\hline Sobre el profesor & PRFR \\
\hline Dominio de contenido. & EDOM \\
\hline Comentarios (retomo) del profesor sobre las evaluaciones. & ERA \\
\hline Retomo del profesor sobre dudas. & SETH \\
\hline Interacción alumno-profesor (chat, foro, atención onlime). & INDI \\
\hline Postura clara y organizada de los contenidos en la plataforma. & ORCS \\
\hline Lecturas / contenidos disponibles por el profesor. & LSD \\
\hline Preocupación con el aprendizaje del alumno. & REAP \\
\hline Evaluaciones concordantes con el plan de enseñanza. & ALAPV \\
\hline Acerca del tutor & TUTOR \\
\hline Proporciona directrices inmediatas para solucionar las dudas sobre el contenido. & NORD \\
\hline Presencia en la atención. & REPEA \\
\hline Información clara y objetiva. & INFOC \\
\hline Preocupación con el aprendizaje del alumno. & PRAT \\
\hline Acompañamiento e incentivo del tutor en las actividades. & AISTAC \\
\hline Sobre la infraestructura del Polo Presencial & INFEST \\
\hline Acceso a ordenadores. & INCOME \\
\hline Acceso a Internet. & ABSENT \\
\hline Horario de atención. & HORUS \\
\hline Acceso al Material Didáctico (Libros). & CMD \\
\hline Sobre el Material Didáctico & MATH \\
\hline Material coherente con el objetivo del curso o disciplina (intencionalidad). & ENTER \\
\hline $\begin{array}{l}\text { El texto (s) por sí solo es capaz de transmitir el mensaje claro y conciso (autoexplicativos y } \\
\text { auto-instructivos). }\end{array}$ & TEXAS \\
\hline $\begin{array}{l}\text { La distribución de los elementos textuales en el espacio limitado de la página } \\
\text { (diagramación, imágenes, tablas, etc.). }\end{array}$ \\
\hline
\end{tabular}

Fuente: Elaborado por los autores.

Se utilizó la escala de Likert de cinco, las cuales variaban de 1 a 5, siendo 1 el punto de menor y 5 de mayor importancia. En primer lugar, los clientes respondieron sobre la expectativa del curso: (1) sin importancia; (2) Poco importante; (3) Indiferente; (4) Muy Importante; (5) Extremadamente importante; y posteriormente la percepción experimentó (recibida) en el curso (1) ordenados; (2) Regular; (3) Indiferente; (4) Muy Bueno; (5) Excelente. La 


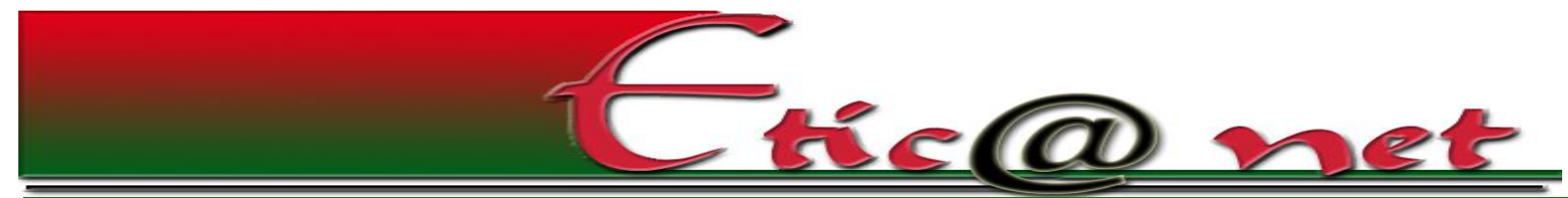

Revista científica electrónica de Educación y Comunicación en la Sociedad del Conocimiento Publicación en línea (Semestral) Granada (España) Época II Vol. 20 (2) Julio-Diciembre de 2020 ISSN: 1695-324X

investigación fue aplicada en el polo presencial de un curso EAD (por exigencia de la institución no será revelado el nombre), ubicado en Rio Grande do Sul, en las (cuatro) clases de curso Técnico en Administración, totalizando un muestreo de 209 alumnos. Los datos fueron tratados utilizando la hoja de cálculo Excel y Statistica 8.0.

En el análisis de los resultados, se utilizó la técnica de análisis factorial (Malhotra, 2001). Para ello debe ser utilizada, la aplicación de la rotación en los factores, para facilitar el entendimiento de los mismos. En la presente investigación se utilizó la Rotación Varimax (Hair et al., 2005) (19), con el objetivo de maximizar el peso de cada variable dentro de cada factor y como criterio de extracción fue definido autovalor mayor que 1.

Se utilizaron los tests Kaiser-Meyer-Olkin (KMO) (Dyer et al., 2007, Olawale y Garwe, 2010) y el de esfericidad de Bartlett (Varol, 2011; Nainggolan et al., 2013) para medir la adecuación de la aplicación del análisis factorial para un determinado conjunto de datos. El KMO presenta valores normalizados (entre 0 y 1.0) y muestra cuál es la proporción de la varianza que las variables presentan en común o la proporción de ésta que son debidas a factores comunes. Es decir, significa si el análisis factorial es apropiado o no. En otras palabras, comprueba el grado de interrelaciones entre las variables.

La prueba, el de Esfericidad de Bartlett se basa en la distribución estadística de Chi-cuadrado y prueba la hipótesis (nula $\mathrm{H} 0$ ) donde, la matriz de correlación es una matriz de identidad (cuya diagonal es 1.0 las demás son igual a cero). Es decir, no hay correlación entre las variables (Pereira, 2001). Los valores de significancia mayores de $(0.100)$ indican que los datos no son adecuados para el tratamiento con el método en cuestión. Es decir, la hipótesis nula no puede ser rechazada. Sin embargo, valores menores de lo indicado permiten rechazar la hipótesis nula. En otras palabras, si ese nivel de significancia es cercano a cero, entonces, la aplicación del análisis factorial es adecuada.

\section{Resultados y Discusión}




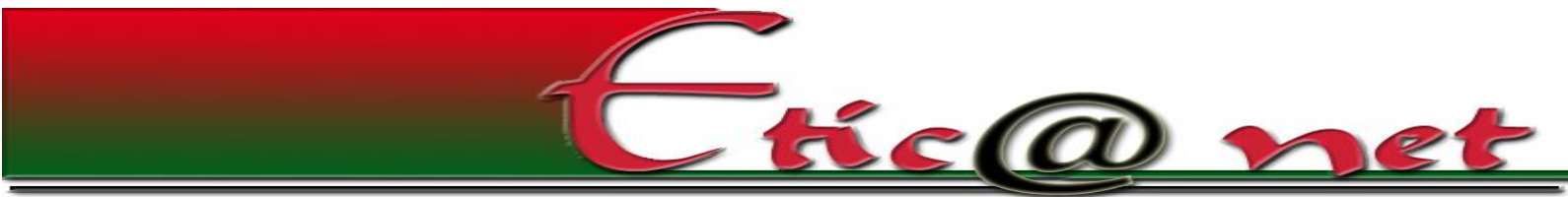

Revista científica electrónica de Educación y Comunicación en la Sociedad del Conocimiento Publicación en línea (Semestral) Granada (España) Época II Vol. 20 (2) Julio-Diciembre de 2020 ISSN: 1695-324X

Este apartado muestra el análisis de los datos recopilados. Los datos se analizaron en dos etapas. La primera analizó la calidad (por medio de la modelo gap) del EAD en una institución. La segunda hizo uso del análisis factorial para refinar (validar) el instrumento de investigación.

Evaluación de la Calidad del EAD - por medio del Modelo de los GAPS (vacíos)

La primera etapa del análisis de los datos se constituyó de la evaluación del nivel de calidad ideal de los servicios desde el punto de vista de los usuarios. Se utilizó el modelo Gap para verificar la relación Servicio Ideal y el percibido. La Tabla 1 muestra el análisis descriptivo de los Gaps (fallas), promedio, desviación estándar, coeficiente de variación.

Tabla 1 - Gaps encontrados en la evaluación de la calidad del EaD

\begin{tabular}{|l|c|c|c|c|c|}
\hline Variables & Expectativa $($ E) Media & DP(E) & Percibido (P) Media & DP (P) & GAP 5 (P-E) \\
\hline Plataforma Moodle & 4.12 & 0.7682 & 4.18 & 0.8396 & 0.06 \\
RADU & 3,88 & 1.0018 & 4.21 & 0.8340 & 0.33 \\
RIVD & 4.00 & 0.8852 & 4.03 & 1.0980 & 0.03 \\
RNA & 3,70 & 0.8309 & 3.98 & 0.7992 & 0.28 \\
ATPP & 4,19 & 0.7062 & 4.22 & 0.7901 & 0.03 \\
AARF & 4,40 & 0.6046 & 4.49 & 0.7213 & 0.09 \\
PLICF & 4,55 & 0.5625 & 4.15 & 1.0972 & -0.40 \\
Profesor & 4.50 & 0.6457 & 4.33 & 0.7129 & -0.17 \\
EDOM & 4,57 & 0.4964 & 4.60 & 0.5974 & 0.03 \\
ERA & 4,53 & 0.5635 & 4.28 & 0.8822 & -0.25 \\
SETH & 4,52 & 0.6286 & 4.07 & 1.0121 & -0.45 \\
INDI & 4,44 & 0.8643 & 4.10 & 0.8323 & -0.34 \\
ORCS & 4,39 & 0.6643 & 4.42 & 0.7237 & 0.03 \\
LSD & 4,56 & 0.5606 & 4.42 & 0.6821 & -0.14 \\
REAP & 4,31 & 0.6519 & 4.33 & 0.7539 & 0.03 \\
ALAPV & 4,41 & 07092 & 4.35 & 0.7951 & -0.06 \\
Tutor & 4,40 & 0.6544 & 4.14 & 0.9781 & -0.26 \\
NORD & 4,40 & 0.6865 & 4.10 & 0.9304 & -0.30 \\
REPEA & 4,56 & 0.6705 & 4.28 & 0.6790 & -0.28 \\
INFOC & 4,24 & 0.7224 & 4.18 & 0.8158 & -0.06 \\
PRAT & 4,33 & 0.7779 & 4.28 & 0.7479 & -0.05 \\
AISTAC & 4,43 & 0.6907 & 3.84 & 0.9817 & -0.59 \\
Infraestructura & 4.38 & 0.8233 & 4.40 & 0.5603 & 0.02 \\
INCOME & 4,61 & 0.5785 & 4.66 & 0.5598 & 0.05 \\
ABSENT & 4,62 & 0.5681 & 4.63 & 0.5659 & 0.01 \\
HORUS & 4,20 & 0.7518 & 4.23 & 0.8534 & 0.03 \\
CMD & 4,07 & 0.8084 & 4.11 & 0.8470 & 0.04 \\
Material Didáctico & 4.14 & 0.7785 & 4.21 & 0.6218 & 0.07 \\
ENTER & 4,27 & 0.8070 & 4.34 & 0.7633 & 0.07 \\
TEXAS & 4,37 & 0.8281 & 3.96 & 0.8841 & -0.41 \\
TELMEX & 3,99 & 0.8933 & 4.30 & 0.8133 & 0.31 \\
& & & & & \\
\hline & & & & & \\
\hline
\end{tabular}

Fuente: Datos de la investigación 


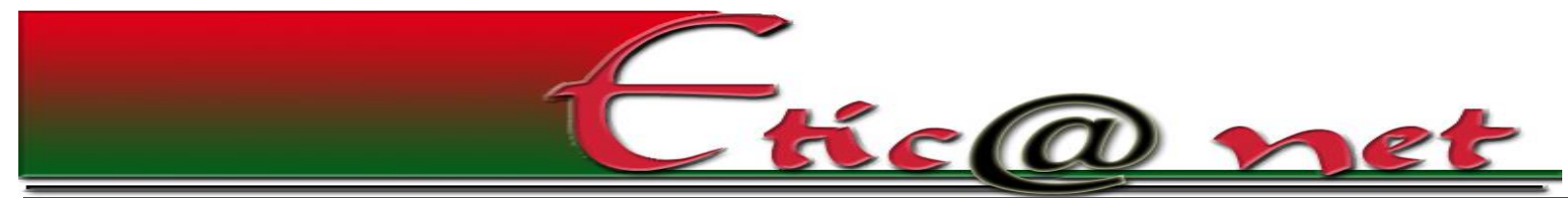

Revista científica electrónica de Educación y Comunicación en la Sociedad del Conocimiento Publicación en línea (Semestral) Granada (España) Época II Vol. 20 (2) Julio-Diciembre de 2020 ISSN: 1695-324X

Los Gaps encontrados están en su mayoría concentrados en dos dimensiones, "profesor" y "tutor". Los mayores gaps fueron encontrados en la dimensión "Tutor" en la variable AISTAC (acompañamiento e incentivo del tutor en las actividades) y 0.41 en TEXAS (El (los) texto (s) por sí solo es (s) capaz de transmitir el mensaje clara y concisa (autoexplicativos y auto-instructivos) de la dimensión "Material didáctico".

Por lo tanto, el material didáctico, tanto desde el punto de vista del enfoque del contenido, como de la forma, debe estar creado según los principios epistemológicos, metodológicos y políticos explicitados en el proyecto pedagógico (Ministerio de Educación, 2007). Esto para facilitar la construcción del conocimiento y mediar la interlocución entre el estudiante y el profesor. Con el objetivo de identificar necesidades de ajustes, buscando su perfeccionamiento.

Se percibe, por los gaps identificados que hay necesidad de reciclaje de los conocimientos de los profesionales, esto es necesario de entrenamiento. Por lo tanto, se observó por los datos que hay oportunidades para la implantación de mejoras. Cabe señalar que, el mercado en el sector servicios es cada vez más competitivo, y las dimensiones de la calidad representadas por los cinco "gaps" pueden ser estrategias competitivas para la empresa.

\section{Refinamiento (validación) del instrumento de evaluación}

Realizada la primera parte del trabajo (evaluar la calidad del EaD) el próximo pasó fue refinar, o sea validar, el instrumento de investigación utilizado. Con el objetivo de hacerlo aún más preciso para reflejar la realidad del objeto de análisis que en este caso es el EaD.

La coherencia interna entre las veintiséis variables fue probada por medio del Alpha de Cronbach, que generó un valor igual a 0.884 , indicando buena confiabilidad de las respuestas atribuidas a las preguntas.

Para la prueba de esfericidad de Bartlett, se obtuvo con la aproximación Chicuadrado un valor de $2.019,427$ con 325 grados de libertad y nivel de 


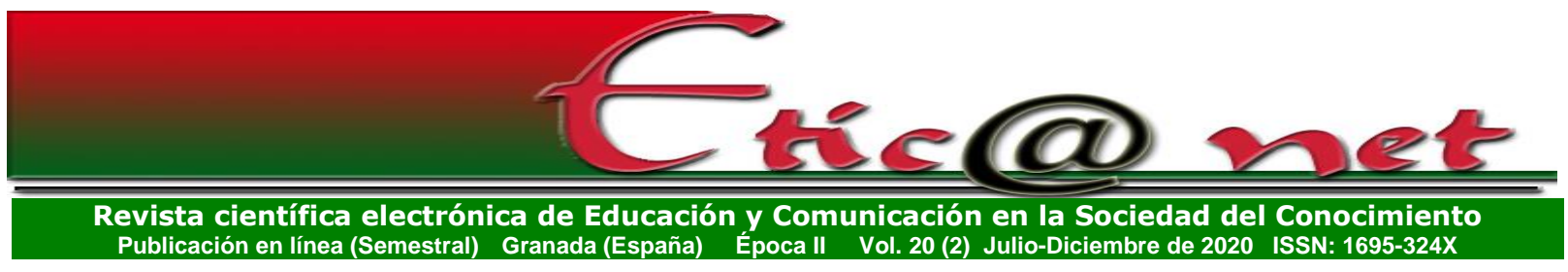

significancia de $p<<0,0001$, rechazando la hipótesis nula de que la matriz de la correlación es una matriz de identidad. La prueba de KMO generó un valor de 0,884 , lo que sugiere una buena adecuación de los datos al análisis factorial. La Tabla 1, también, muestra el valor de la comunalidad para cada variable. La comunalidad es la cantidad total de varianza que una variable original comparte con todos los demás análisis (Hair et al., 2006 y Stefano, 2013). Las comunalidades varían entre 0 y 1 (Tabla 2), siendo 0 cuando los factores comunes no explican ninguna varianza de la variable y 1 cuando explican toda su varianza.

Tabla 2 - Cargas factoriales, después de la rotación Varimax Normalizada.

\begin{tabular}{|c|c|c|c|c|c|}
\hline Abreviatura & Factor 1 & Factor 2 & Factor 3 & Factor 4 & Comunalidad \\
\hline RADU & 0.3326 & 0.2360 & -0.0503 & 0.6194 & 0.664 \\
\hline RIVD & 0.4822 & 0.2467 & -0.0435 & 0.4131 & 0.594 \\
\hline RNA & 0.4066 & 0.2344 & 0.1433 & 0.3913 & $0.609^{-}$ \\
\hline ATPP & -0.0408 & 0.2109 & 0.0958 & 0.7696 & 0.681 \\
\hline AARF & 0.0417 & 0.2105 & -0.0285 & 0.7657 & 0.674 \\
\hline PLICF & 0.3860 & $0.2280^{\circ}$ & -0.0284 & 0.5280 & 0.553 \\
\hline $\mathrm{EDOM}$ & 0.2925 & 0.0889 & 0.14684 & 0.6480 & 0.672 \\
\hline ERA & 0.6444 & 0.1876 & -0.1269 & 0.1254 & 0.563 \\
\hline SETH & 0.0062 & 0.5745 & $0.4146^{-}$ & -0.0454 & 0.583 \\
\hline $\mathrm{NDI}^{-}$ & 0.2011 & 0.4234 & 0.4589 & -0.0119 & 0.600 \\
\hline ORCS & 0.7620 & -0.0126 & -0.1488 & 0.2218 & 0.695 \\
\hline LSD & 0.6350 & 0.2702 & 0.1247 & $0.1310^{-}$ & 0.566 \\
\hline REAP & 0.5222 & 0.1192 & 0.0399 & 0.4843 & 0.600 \\
\hline ALAPV & 0.6602 & 0.0880 & 0.1139 & $-0.0530^{\circ}$ & 0.538 \\
\hline NORD & 0.3031 & 0.3688 & 0.0136 & 0.2298 & 0.399 \\
\hline REPEA & 0.3590 & $0.4691^{-}$ & -0.0497 & 0.2504 & 0.520 \\
\hline INFOC & 0.1331 & 0.7645 & 0.1561 & $0.1240^{\circ}$ & 0.648 \\
\hline PRAT & 0.2207 & 0.7028 & $0.0324^{-}$ & 0.1919 & 0.601 \\
\hline AISTAC & 0.0467 & 0.7306 & 0.1750 & 0.1622 & 0.619 \\
\hline INCOME & 0.1918 & 0.6934 & 0.0350 & 0.1863 & 0.593 \\
\hline ABSENT & 0.0349 & 0.7614 & -0.0996 & 0.2496 & 0.705 \\
\hline HORUS & 0.2093 & 0.6060 & $-0.2790^{\circ}$ & 0.2269 & 0.652 \\
\hline $\mathrm{CMD}$ & 0.2208 & 0.6094 & -0.4616 & 0.1610 & 0.695 \\
\hline ENTER & $-0.0230^{\circ}$ & 0.0308 & -0.3099 & 0.1084 & 0.885 \\
\hline TEXAS & -0.1513 & 0.0534 & 0.6515 & 0.2250 & 0.702 \\
\hline TELMEX & 0.0568 & 0,038100 & 0.5834 & 0.2121 & 0.716 \\
\hline $\begin{array}{l}\text { Autovalores } \\
\text { (eigeroulues) }\end{array}$ & 7.7715 & 2,237244 & 1.7825 & 1.3975 & \\
\hline$(\%)$ de varianza & 30.00 & 8,60 & 6.85 & 5.37 & \\
\hline $\begin{array}{c}\text { Autoxalores } \\
\text { acumulados (\%) }\end{array}$ & 7.77 & 10,01 & 11.79 & 13.19 & \\
\hline $\begin{array}{c}\text { Varianza Acumulada } \\
(\%)\end{array}$ & 30.00 & 38,50 & 45.35 & 50.72 & \\
\hline
\end{tabular}

Fuente: Datos de la investigación

A continuación, se muestran las Figuras 3 y 4 que muestran los planes factoriales. Sólo el Factor 1, como muestra la Figura 4, contribuye con $30.00 \%$ de la variabilidad total de los datos, siendo así, el de mayor importancia en el 


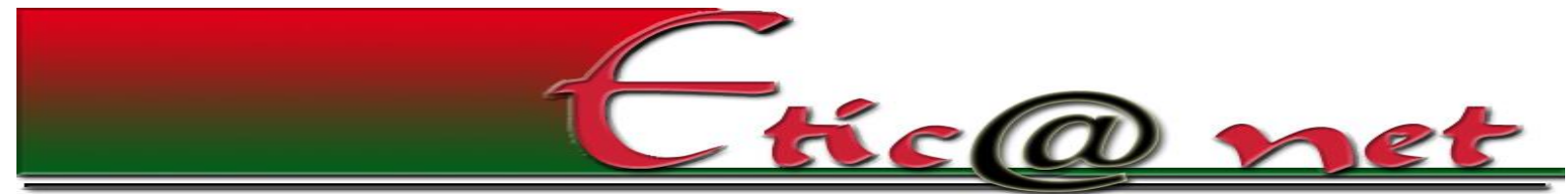

Revista científica electrónica de Educación y Comunicación en la Sociedad del Conocimiento Publicación en línea (Semestral) Granada (España) Época II Vol. 20 (2) Julio-Diciembre de 2020 ISSN: 1695-324X

análisis, y se encuentra representado en el eje de las abscisas. Las variables representativas en cada factor están marcadas con un círculo para una mejor visualización. En el caso de que se produzca un cambio en la calidad de la muestra, se debe tener en cuenta que, en el factor 1 (en el eje de las abcisas) la variable más representativa es la ORCS (entrada clara y organizada de los contenidos en la plataforma) la cual cuestiona la forma en que los materiales son publicados en Moodle. Otra variable que se destaca es ALAPV (evaluaciones concordantes con el plan de enseñanza) donde se cuestiona si las evaluaciones concuerdan con lo que se presenta en el plano de enseñanza.

Figura 3 - Representación gráfica del Factor 1 versus Factor 2

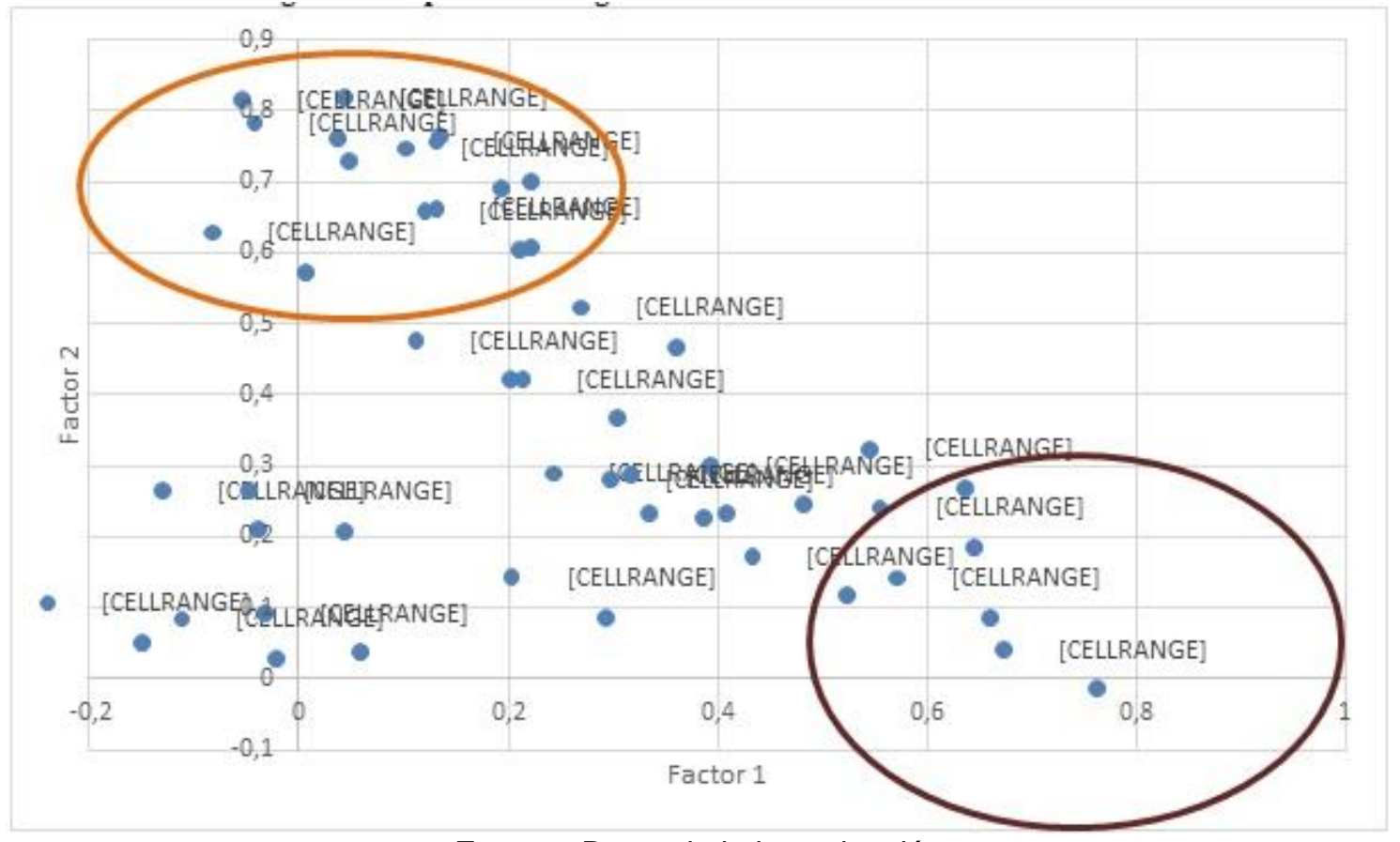

El factor 2 (en el eje de las ordenadas) explica el $8.60 \%$ de la variabilidad total del conjunto de los datos. Las variables más significativas son INFOC (informaciones claras y objetivas); ABSENT (acceso a Internet) y; AISTAC (acompañamiento e incentivo del tutor en las actividades), siendo que todas esas variables forman parte de la dimensión "Tutor". En realidad, estas variables y otras en destaque se refieren a la capacidad didáctico-pedagógica (Zanella, 2008) del tutor. 


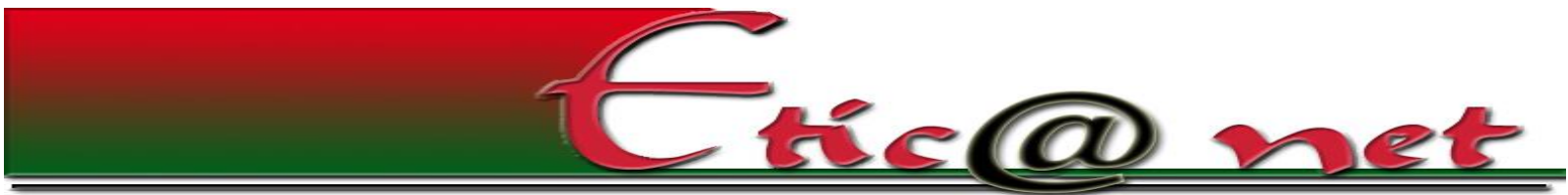

Revista científica electrónica de Educación y Comunicación en la Sociedad del Conocimiento Publicación en línea (Semestral) Granada (España) Época II Vol. 20 (2) Julio-Diciembre de 2020 ISSN: 1695-324X

El hecho 3 (en el eje de las abcisas) contribuye con el $6.85 \%$ de la explicación de la variabilidad de los datos. El factor es representado por las siguientes variables: TEXAS (el (los) texto (s) por sí solo es capaz de transmitir el mensaje claro y conciso), o sea si los textos son autoexplicativos y auto instructivos a otra; TELMEX (La distribución de los elementos textuales en el espacio limitado de la página) la cual se refiere a la forma de cómo se distribuyen los elementos de diagramación, imágenes, tablas, etc. Ambas variables se refieren a la dimensión material didáctica.

\section{Figura 4 - Representación gráfica del Factor 3 versus Factor 4}

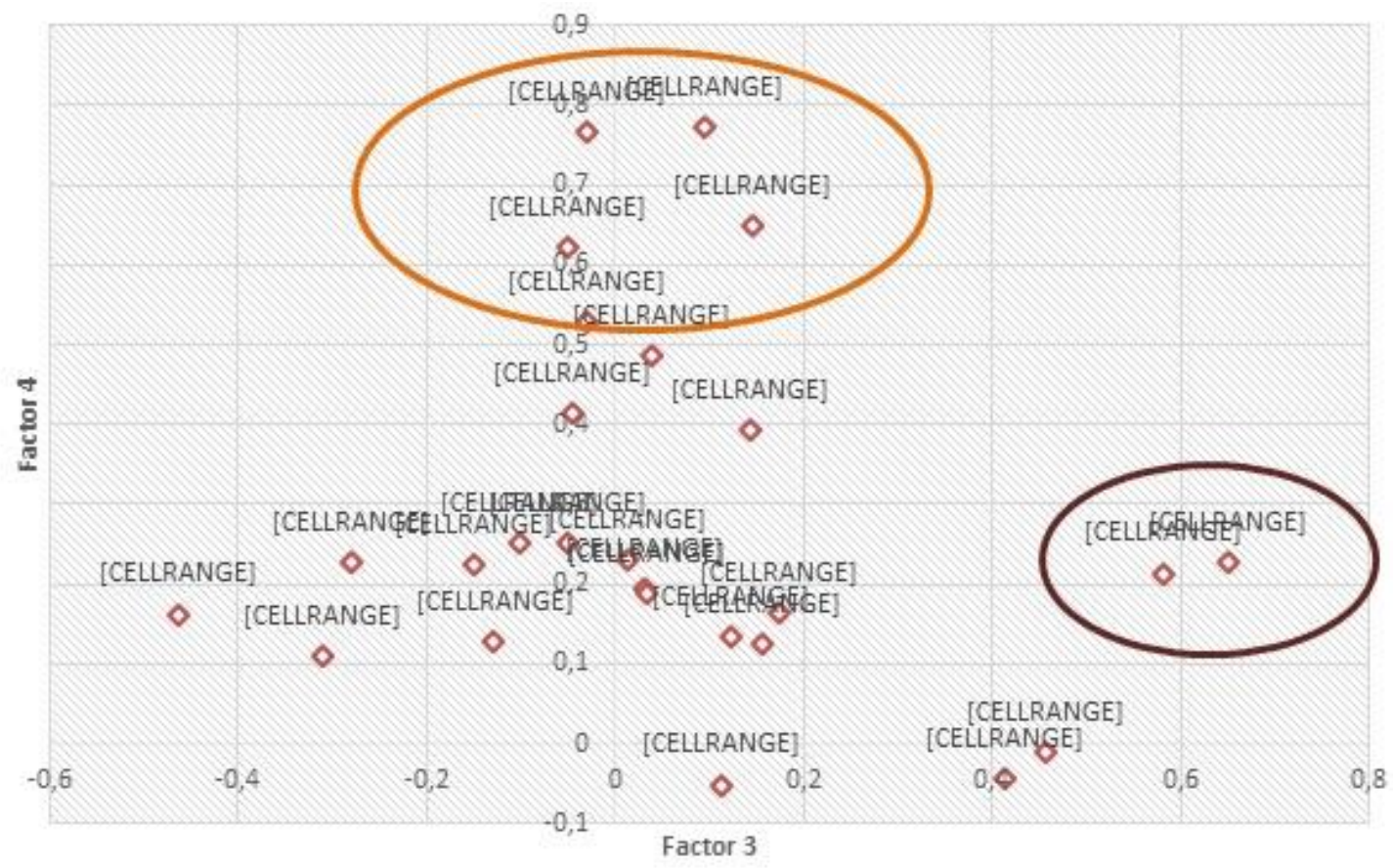

Fuente: Datos de la investigación

Y, por último, el factor 4, representado en la Figura y ubicado en el eje de las ordenadas, está representado por las siguientes variables: RADU (uso de los recursos de audio); ATPP (actualización de la plataforma Moodle); AARF (acceso a archivos en cualquier formato (PDF, DOC, PPT, etc.) o enlaces externos (URL), PLICF (plataforma funcional, instructiva y clara) ambas de la dimensión "Plataforma Moodle" y "EDOM (dominio de contenido) dimensión "profesor". 


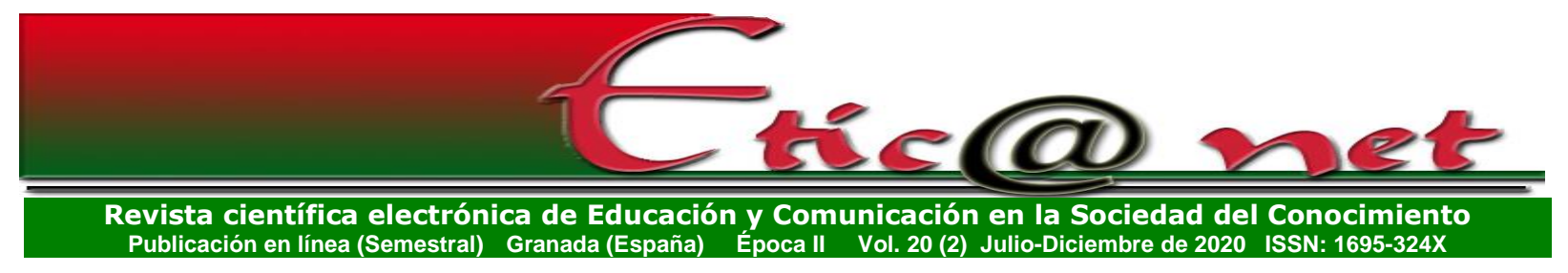

Por lo tanto, por medio del análisis factorial posibilitó obtener una nueva estructura (en las dimensiones) para evaluar la calidad del EaD. El cuadro 4 muestra la estructura inicial y después del uso del análisis factorial.

Tabla 4 - Comparación de las variables de instrumento de investigación para evaluar la calidad del EaD (antes y después)

\begin{tabular}{|c|c|c|}
\hline \multirow[t]{2}{*}{ ANTES } & Descripción de la variable & \multirow[t]{2}{*}{ DESPUES } \\
\hline & Dimensión Plataforma Moodle (DMT) & \\
\hline $\mathrm{X}$ & Uso de las funciones de audio (RADU) & $\mathrm{X}$ \\
\hline $\mathrm{X}$ & Uso de las funciones de video (RIVD) & \\
\hline $\mathrm{X}$ & Uso de las funciones de animación(RNA) & \\
\hline $\mathrm{X}$ & Actualizaciónde la plataforma Moodle (ATPP) & $\bar{X}$ \\
\hline $\mathrm{X}$ & $\begin{array}{l}\text { Acces o a archivos en cualquier formato (PDF, DOC, PPT, etc.) o enlaces } \\
\text { externos (URL) (AARF) }\end{array}$ & $\mathrm{X}$ \\
\hline \multirow[t]{2}{*}{$\mathrm{X}$} & Plataforma funcional, instructiva y clara (PLICF) & $\mathrm{X}$ \\
\hline & Sobre el profesor (PRFR) & \\
\hline $\mathrm{X}$ & Dominio de contenido (EDOM) & $\mathrm{X}$ \\
\hline $\mathrm{X}$ & La retroalimentación del profes or sobre las evaluaciones (ERA) & $\mathrm{X}$ \\
\hline $\mathrm{X}$ & Retorno del profes or so bredudas (SETH) & $\mathrm{X}$ \\
\hline $\mathrm{X}$ & Interacción alumno-profesor (chat, foro, atención online) (INDI) & \\
\hline $\mathrm{X}$ & Po stura clara y organizada de los contenidos en la plataforma(ORCS) & $\mathrm{X}$ \\
\hline $\mathrm{X}$ & Lecturas / contenidos disponibles por el profesor (LSD) & $\bar{X}$ \\
\hline $\mathrm{X}$ & Preocupación con el aprendizaje del alumno (REAP) & $\mathrm{X}$ \\
\hline \multirow[t]{2}{*}{$\mathrm{X}$} & Evaluaciones concordantes con el plan de ens enanza (ALAPV) & $\mathrm{X}$ \\
\hline & $\begin{array}{l}\text { Sobre el tutor (TUTOR) } \\
\end{array}$ & \\
\hline $\mathrm{X}$ & $\begin{array}{l}\text { Proporcionadirectrices inmediatas para solucionar las dudas sobre el } \\
\text { contenido (NORD) }\end{array}$ & \\
\hline $\mathrm{X}$ & Presencia en la atención (REPEA) & \\
\hline $\mathrm{X}$ & Información claray objetiva (INFOC) & $\mathrm{X}$ \\
\hline $\mathrm{X}$ & Preocupación con el aprendizaje del alumno (PRAT) & $\mathrm{X}$ \\
\hline \multirow[t]{2}{*}{$\mathrm{X}$} & Acompanamiento e incentivo del tutor en las actividades (AISTAC) & $\mathrm{X}$ \\
\hline & Sobre la Infraestructura del Polo Presencial (INFEST) & \\
\hline $\mathrm{X}$ & Acces o a equipos (INCOME) & $\mathrm{X}$ \\
\hline $\mathrm{X}$ & Acces o a Internet (ABSENT) & $\mathrm{X}$ \\
\hline $\mathrm{X}$ & Horario de atención(HORUS) & $\mathrm{X}$ \\
\hline $\mathrm{X}$ & Acces o alMaterial Didáctico (Libros) (CMD) & \\
\hline $\mathbf{n}$ & $\begin{array}{l}\text { Sobre el Material Didáctico (MATH) } \\
\end{array}$ & \\
\hline $\bar{X}$ & $\begin{array}{l}\text { Material coherente con el objetivo del curso o disciplina } \\
\text { (intencionalidad) (ENTER) }\end{array}$ & \\
\hline $\mathrm{X}$ & $\begin{array}{l}\text { El texto (s) por si solo es capazde transmitir el mensaje claro y conciso } \\
\text { (autoesplicatives y auto-instructivos) (TEXAS) }\end{array}$ & $\mathrm{X}$ \\
\hline $\mathrm{X}$ & $\begin{array}{l}\text { La distribución de los elementos textuales en el espacio limitado de la } \\
\text { página (diagramación, imágenes, tablas, etc.) (TELMEX) }\end{array}$ & $\mathrm{X}$ \\
\hline
\end{tabular}

Fuente: Elaborado por los autores

Por lo tanto, el análisis factorial proporcionó que, si se adapta de forma más precisa el instrumento de investigación utilizado, esto hizo que hubiera mayor homogeneidad entre las variables de cada dimensión. 


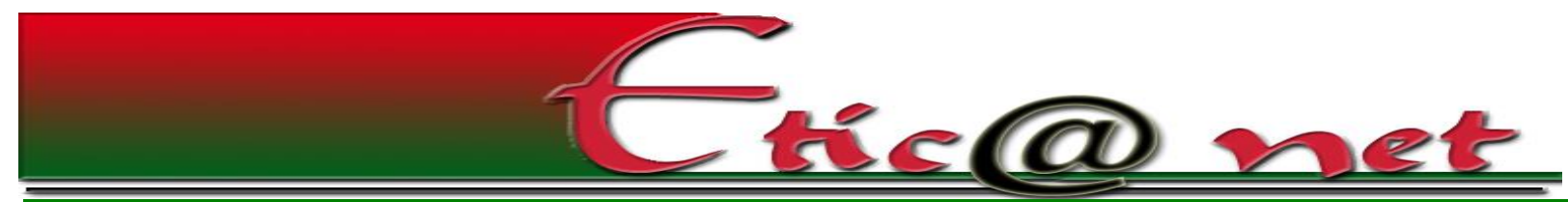

Revista científica electrónica de Educación y Comunicación en la Sociedad del Conocimiento Publicación en línea (Semestral) Granada (España) Época II Vol. 20 (2) Julio-Diciembre de 2020 ISSN: 1695-324X

\section{Consideraciones finales}

El presente estudio tuvo como objetivo evaluar la calidad de la Enseñanza a Distancia - EAD, por medio del uso de la escala SERVQUAL y también refinar (validar) el instrumento de evaluación, para evaluar la calidad del EaD, para perfeccionarlo por medio de técnicas del análisis factorial. Se han destacado las dimensiones de la calidad que superan o no las expectativas de los alumnos.

Para la recolección de datos se elaboró un cuestionario adaptado del tipo SERVQUAL con las dimensiones de la calidad (Plataforma Moodle, Profesor, Tutor, Infraestructura del Polo Presencial y Material Didáctico) que primero fue validado con especialistas del área (profesores de la Institución donde fue realizada la búsqueda). Se realizaron tres rondas de entrevistas con los profesores hasta que se llegara a un cuestionario apto para visualizar la realidad del objeto de estudio.

Primero, por medio del modelo gap se identificaron las lagunas que carecen de mejoras. De esta forma se encontraron lagunas en las siguientes dimensiones y variables:

- Profesor - ERA (feedback del profesor sobre las evaluaciones.); SETH (retorno del profesor sobre dudas); INDI (Interacción alumno-profesor); LSD (lecturas / contenidos disponibles por el profesor); REAP (preocupación por el aprendizaje del alumno.); ALAPV (evaluaciones concordantes con el plan de enseñanza).

- Tutor - NORD (proporciona orientaciones inmediatas para subsanar las dudas sobre el contenido); REPEA (presteza en la atención); INFOC (información clara y objetiva); PRAT (preocupación por el aprendizaje del alumno); AISTAC (seguimiento e incentivo del tutor en las actividades).

- Material didáctico - TEXAS (EI (los) texto (s) por sí solo es (s) capaz (es) de transmitir el mensaje claro y conciso).

De esta forma los resultados dejan claro que, en algunos puntos, las expectativas no se exceden, existiendo necesidades de cambios, 


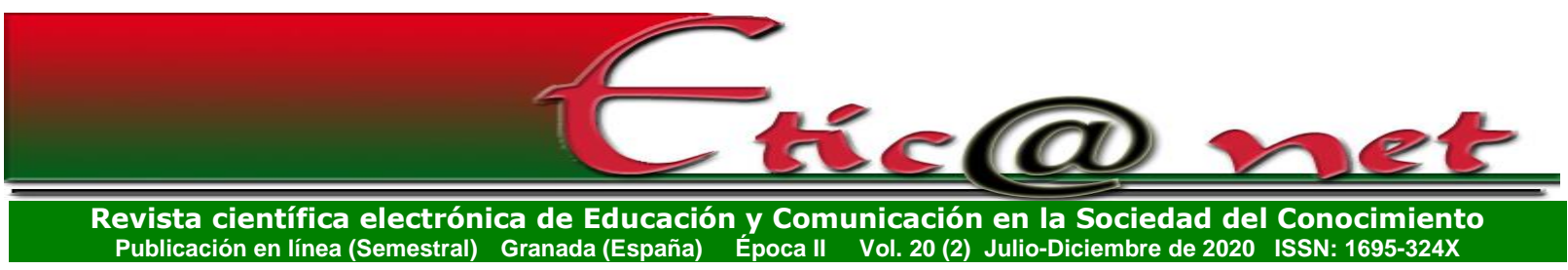

principalmente, en lo que se refiere a la atención de la empresa, siendo un factor importante para el éxito en ambientes de servicios.

En cuanto a las técnicas de análisis factorial utilizadas para validar el instrumento de evaluación de la calidad del $\mathrm{EaD}$, éstas posibilitaron perfeccionar el instrumento de investigación que pasó a tener una nueva estructura (Cuadro 5).

Cuadro 5 - Variables del nuevo instrumento de investigación

\begin{tabular}{|c|}
\hline Descripción de la variable \\
\hline Dimensión Plataforma Moodle (DMT) \\
\hline 1. 1. Uso de las funciones de audio (RADU) \\
\hline 2. 2. Actualización de la plata forma Moodle (ATPP) \\
\hline $\begin{array}{l}\text { 3. 3. Acceso a archivos en cualquier formato (PDF, DOC, PPT, etc.) o enlaces extemos } \\
\text { (URL) (AARF) }\end{array}$ \\
\hline 4. 4. Plata forma funcional, instructiva y clara (PLICF) \\
\hline $\begin{array}{l}\text { Sobre el profesor (PRFR) } \\
\end{array}$ \\
\hline 5. 1. Dominio de contenido (EDOM) \\
\hline 6. 2. Feedback(retomo) del profesor sobre las evaluaciones (ERA) \\
\hline 7. 3. Retomo del profesor sobre dudas(SETH) \\
\hline 8. 4. Postura clara y organizada de los contenidos en la plata forma (ORCS) \\
\hline 9. 5. Lecturas / contenidos disponibles por el profesor (LSD) \\
\hline 10. 6. Preocupación con el aprendizaje del alumno (REAP) \\
\hline 11. 7. Evaluaciones que concuerdan con el plan de enseñanza (ALAPV) \\
\hline Sobre el tutor (TUTOR) \\
\hline 12. 1. Información clara y objetiva (INFOC) \\
\hline 13. 2. Preocupación con el aprendizaje del alumno (PRAT) \\
\hline 14. 3. Acompañamiento e incentivo del tutor en las actividades (AISTAC) \\
\hline Sobre la Infraestructura del Polo Presencial (INFEST) \\
\hline 15. 1. Acceso a equipos (INCOME) \\
\hline 16. 2. Acceso a Intemet (ABSENT) \\
\hline 17. 3. Horario de atención(HORUS) \\
\hline Sobre el Material Didáctico (MATH) \\
\hline $\begin{array}{l}\text { 18. 1. El texto (s) por si solo es capaz de transmitir el mensaje claro y conciso } \\
\text { (autoexplicativosy auto-instructivos)(TEXAS) }\end{array}$ \\
\hline $\begin{array}{l}\text { 19. 2. La distribución de los elementos textuales en el espacio limitado de la página } \\
\text { (diagramación, imágenes, tablas, etc.) (TELMEX) }\end{array}$ \\
\hline
\end{tabular}

Fuente: Elaborado por los autores

Como implicación gerencial, principal, se recomienda que los gestores deban garantizar que los empleados estén bien entrenados y comprender el nivel de servicio que la empresa espera ofrecer para sus clientes, en este caso los alumnos. Pues, la EaD basada en Internet surge como una modalidad de 


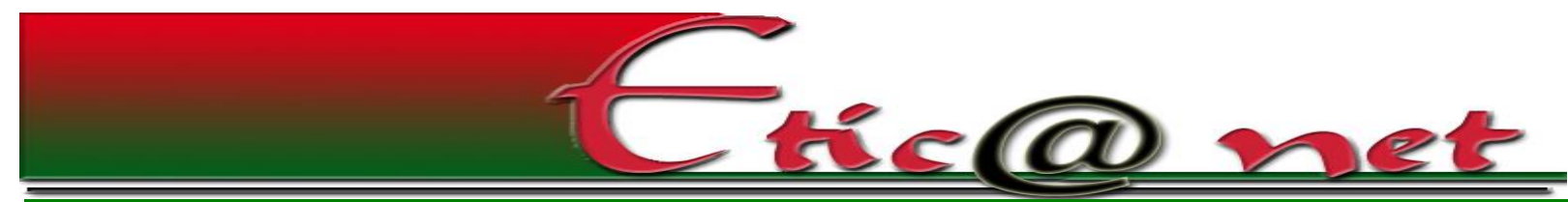

Revista científica electrónica de Educación y Comunicación en la Sociedad del Conocimiento Publicación en línea (Semestral) Granada (España) Época II Vol. 20 (2) Julio-Diciembre de 2020 ISSN: 1695-324X

educación adecuada a las nuevas demandas educativas que caracterizan al mundo globalizado. Y, eso requiere que las empresas satisfagan a sus clientes y superen sus expectativas, de esta forma manteniendo una ventaja competitiva en el mercado.

Por lo tanto, a partir de esas consideraciones, la empresa investigada podrá delinear las áreas de actuación referentes a sus puntos de divergencia entre la expectativa y percepción de la calidad.

\section{Referencias Bibliográficas}

Akbaba, A. (2006), "Measuring service quality in the hotel industry: a study in a business hotel in Turkey". International Journal of Hospitality Management, 25 (2), pp. 170-192.

Almeida, M. E. B. (2003), "Educação a distância na internet: abordagens e contribuições dos ambientes digitais de aprendizagem". Educação e Pesquisa, 29 (2), pp. 327-340.

Amarilla Filho, P. (2011), "Educação a distância: Uma abordagem metodológica e didática a partir dos ambientes virtuais". Educ. Rev., Belo Horizonte, 27 (2).

Cantu-Ortiz, F. J. (2014), "Advancing artificial intelligence research and dissemination through conference series: benchmark, scientific impact and the MICAI experience". Expert Systems with Applications, 41 (3), pp. 781-785.

Capeletti, A. M. (2014), "Ensino a Distância desafios encontrados por alunos do ensino superior". Revista Eletrônica Saberes da Educação, 5 (1).

Carús, L. (2014), "Causes of accidents in terrain parks: an exploratory factor analysis of recreational freestylers' views". Wilderness \& Environmental Medicine, 25 (1), pp. 94-98.

Das, G. (2014), "Linkages of retailer awareness, retailer association, retailer perceived quality and retailer loyalty with purchase intention: a study of Indian food retail brands". Journal of Retailing and Consumer Services, 21 (3), pp. 284-292.

Diana, T. (2014), "Validating delay constructs: an application of confirmatory factor analysis". Journal of Air Transport Management, 35, pp. 87-91. 


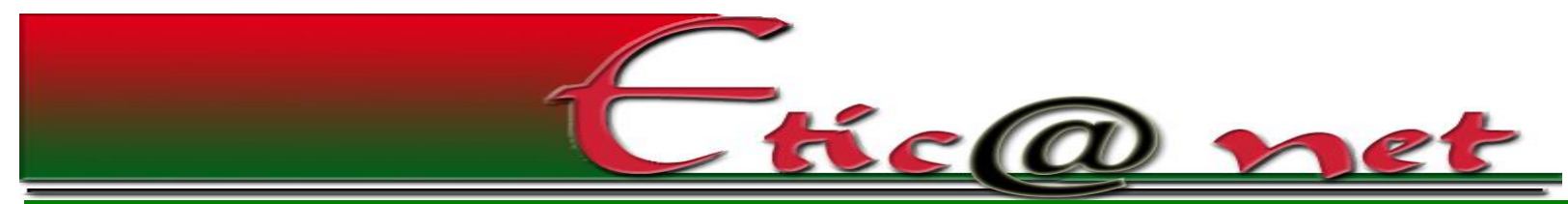

Revista científica electrónica de Educación y Comunicación en la Sociedad del Conocimiento Publicación en línea (Semestral) Granada (España) Época II Vol. 20 (2) Julio-Diciembre de 2020 ISSN: 1695-324X

Dyer, P. - Gursoy, D. - Sharma, B. y Carter, J. (2007), "Structural modeling of resident perceptions of tourism and associated development on the Sunshine Coast, Australia". Tourism Management, 28 (2), pp. 409-422.

Edward, M. y Sahadev, S. (2011), "Role of switching costs in the service quality, perceived value, customer satisfaction and customer retention linkage". Asia Pacific Journal of Marketing and Logistics, 23 (3), pp. 327-345.

Fryer, L. K. H. - Bovee, N. y Nakao, K. (2014), "E-learning: reasons students in language learning courses don't want to". Computers \& Education, 74, pp. 26-36.

Fuentes, J. A. (2011). Características de la actividad cívica de los adolescentes y jóvenes españoles: e-ciudadanía. Revista Electrónica Interuniversitaria de Formación del Profesorado, 14 (2), 115-126.

Gallego, M. J. (1996), La tecnología Educativa en acción. Granada: Force.

Ghobadian, A. - Speller, S. y Jones, M. (1994), "Service quality: concepts and models". International Journal of Quality \& Reliability Management, 11 (9), pp. 43-66.

González, I.; Quintero, B.; Mendigutxia-Sorabilla, G.; Reche, E. y Fuentes, J. A. (2020). Construction of an Instrument for the Evaluation of the Effects of Information and Communication Technologies among Young People. Sustainability 12 (9): 3785. DOI: https://doi.org/10.3390/su12093785

González-Aguilera, D. et al. (2013), "Accuracy assessment of vehicles surface area measurement by means of statistical methods". Measurement, 46 (2), pp. 1009-1018.

Guha, A. S. y Maji, S. (2008), "E-learning: the latest spectrum in open and distance learning". Social Responsibility Journal, 4, pp. 297-305.

Hair, J. et al. (2006), Análise multivariada de dados, (5 ed.). Porto Alegre, Bookman.

Hakala, H. (2011), "Strategic Orientations in management literature: three approaches to understanding the interaction between market, technology, entrepreneurial and learning orientations". International Journal of Management Reviews, 13 (2), pp. 199-217.

Hamer, L. O. A. (2006), "Confirmation perspective on perceived service quality". Journal of Services Marketing, 20 (4), pp. 219-232.

Johnston, R. (1995), "The determinants of service quality: satisfiers and dissatisfiers". International Journal of Service Industry Management, 6 (5), pp. 53-71. 


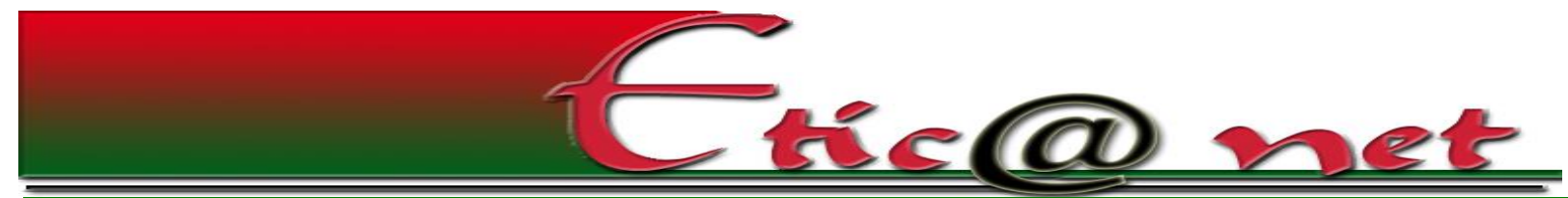

Revista científica electrónica de Educación y Comunicación en la Sociedad del Conocimiento Publicación en línea (Semestral) Granada (España) Época II Vol. 20 (2) Julio-Diciembre de 2020 ISSN: 1695-324X

Johnston, R. (2005), "Service operations management: return to roots". Internacional Journal of Operations \& Production Management, 25 (12), pp. 1278-1297.

Kakoty, S. - Lal, M. y Sarma, S. K. (2011), "E-learning as a research area: an analytical approach". International Journal of Advanced Computer Science and Applications (IJACSA), 2 (9), pp. 144-148.

Klaus, P. y Maklan, S. (2012), "A Multiple-Item Scale for Assessing Service Experience". Journal of Service Management, 23 (1), pp. 1-1.

Kokkinis, G. - Mihiotis, A. y Pappis, C. P. (2006), "Freight forwarding in Greece: Services provided and choice criteria". EuroMed Journal of Business, 1 (2), pp. 64-81.

Lasch, R. y Janker, C. G. (2005), "Supplier selection and controlling using multivariate analysis". International Journal of Physical Distribution \& Logistics Management, 35 (6), pp. 409-425.

Liyanage, C. - Elhag, T. - Ballal, T. y Li, Q. (2009), "Knowledge communication and translation: a knowledge transfer model". Journal of Knowledge Management, 13 (3), pp. 118-31.

Löfgren, M. - Witell, L. y Gustafsson, A. (2008), "Customer satisfaction in the first and second moments of truth". Journal of Product \& Brand Management, 17 (7), pp. 463-474.

Löfgren, M. (2005), "Winning at the first and second moments of truth: an exploratory study". Managing Service Quality, 15 (1), pp. 102-115.

Malhotra, N. (2001), Pesquisa de marketing: uma orientação aplicada, (3 ed.). Porto Alegre, Bookman.

Martínez, M. D.; Chávez, D. R. y Fuentes, J. A. (2013). Los Recursos Educativos Abiertos para la formación en el trabajo. Etic@net, Revista científica electrónica de Educación y Comunicación en la Sociedad del Conocimiento, 13 (2), 238-259.

Martínez Caro, E. (2009), "La gestión del conocimiento a través del e-learning: un enfoque basado en escenarios". Investigaciones Europeas de Dirección y Economía de la Empresa, 15 (13), pp. 29-44.

Ministério da Educação (207), Referencias de qualidade para educação superior a distancia. Brasília, Secretaria de Educação a Distância.

Mireles, M. C.; Fuentes, J. A. y Ortega, J. A. (2018). Equipment, educational leves, uses of mobile pone of doctoral students from Pedagogic 


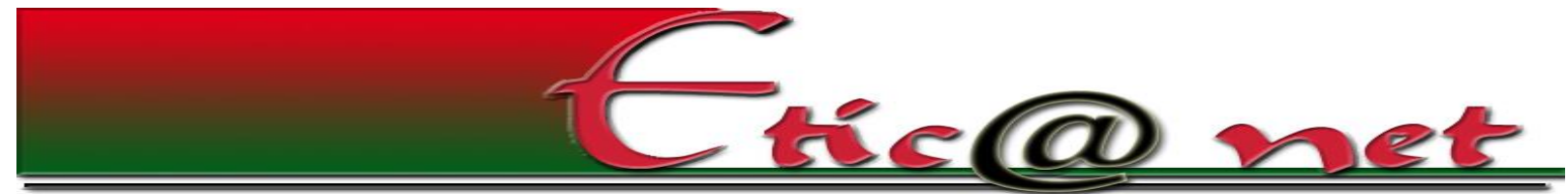

Revista científica electrónica de Educación y Comunicación en la Sociedad del Conocimiento Publicación en línea (Semestral) Granada (España) Época II Vol. 20 (2) Julio-Diciembre de 2020 ISSN: 1695-324X

Experimental Libertador University. Pixel-Bit. Revista de Medios y Educación, 52, 229-243.

Moliner, M. A. (2009), "Loyalty, perceived value and relationship quality in healthcare services". Journal of Service Management, 20 (1), pp. 76-97.

Nainggolan, D. et al. (2013), "Farmer typology, future scenarios and the implications for ecosystem service provision: a case study from southeastern Spain". Reg Environ Change, 13, pp. 601-614.

Noguera, A. (2014), "First Spanish Version of the memorial delirium assessment scale: psychometric properties, responsiveness, and factor loadings". Journal of Pain and Symptom Management, 47 (1), pp. 189197.

Öcal, M. E. et al. (2007), "Industry financial ratios: application of factor analysis in Turkish construction industry". Building and Environment, 42 (1), pp. 385-392.

Olawale, F. y Garwe, D. (2010), "Obstacles to the growth of new SMEs in South Africa: a principal component analysis approach". African Journal of Business Management, 4 (5), pp. 729-738.

Ooi, K. (2014), "TQM: A facilitator to enhance knowledge management? A structural analysis". Expert Systems with Applications, 41 (11), pp. 51675179.

Parasuraman, A. - Zeithaml, V. A. \& Berry, L. L. (1985), "A conceptual model of service quality and its implications for future research". Journal of Marketing, 49 (4), pp. 41-50.

Parasuraman, A. - Zeithaml, V. A. \& Berry, L. L. (1988), "SERVQUAL: a multiple-item scale for measuring consumer perceptions of service quality". Journal of Retailing, 64 (1), pp. 12-40.

Parasuraman, A. (2004), "Assessing and improving service performance for maximum impact: insights from a two-decade-long research journey". Performance Measurement and Metrics, 5, pp. 45-52.

Pareja, J. A.; Fernández, M. y Fuentes, J. A. (2019). Innovación metodológica en posgrado: Aprendizaje Basado en Proyectos. Profesorado. Revista de Currículum y Formación de Profesorado, 23 (3), 113-128. DOI: https://doi.org/10.30827/profesorado.v23i3.9497

Pareja, J. A.; Fuentes, J. A.; Fernández, M. y Hernández, A. M. (2017). Tutoring innovation in the Degree of Pedagogy: the proyect "Multidisciplinary Organization for European Adaptation to Higher Education". En L. 


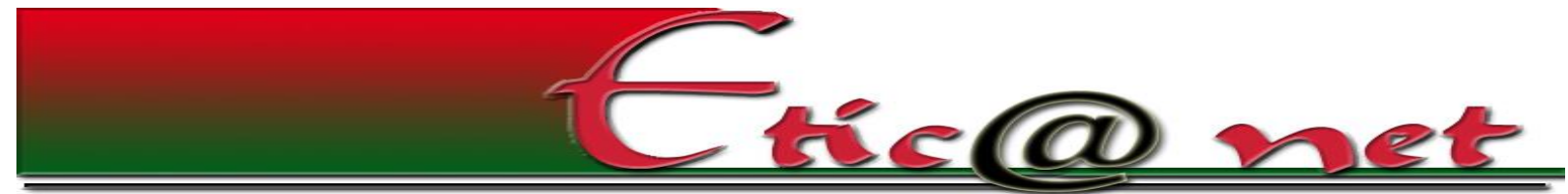

Revista científica electrónica de Educación y Comunicación en la Sociedad del Conocimiento Publicación en línea (Semestral) Granada (España) Época II Vol. 20 (2) Julio-Diciembre de 2020 ISSN: 1695-324X

Gómez; A. López e I. Candel (Eds.). EDULEARN17 Proceedings, 12211225. IATED Academy

Park, B. - Moreno, R. - Seufert, T. y Brünken, R. (2011), "Does cognitive load moderate the seductive details effect? a multimedia study". Computers in Human Behavior, 27 (1), pp. 5-10.

Patto, M. H. S. (2013), "O ensino a distância e a falência da educação". Educação e Pesquisa, 39 (2).

Pereira, J. C. R. (2001), Análise de dados qualitativos: estratégias metodológicas para as ciências da saúde, humanas e sociais. São Paulo, EDUSP.

RAE. Real Academia Española. Institución (2019), Disponible en https://dle.rae.es/?w=excelencia.

Rinaldi, A. M. (2014), "A multimedia ontology model based on linguistic properties and audio-visual features". Information Sciences, 277, pp. 234-246.

Sabbatini, R. M. E. (2014), Ambiente de Ensino e Aprendizagem via Internet: a Plataforma Moodle. Instituto Edumed - Educação à Distância. Disponible en: $\quad$ http://www.ead.edumed.org.br/file.php/1/PlataformaMoodle.pdf. (08/06/2014).

Schuelter, W. (2005), "Ambiente virtual de aprendizagem: reflexões sobre as mudanças na metodologia de ensino e o papel do profesor". $12^{\circ}$ Congresso $A B E D$, pp. 1-9, Anais, Universidade de Santa Catarina UNISUL.

Seattler, P. (2004), The evolution of american educational technology, Greenwich, IAP.

Shang, C. - Yang, F. y Huang Lyu, D. W. (2014), "Data-driven soft sensor development based on deep learning technique". Journal of Process Control, 24 (3), pp. 223-233.

Snoj, B. - Korda, A. P. y Mumel, D. (2004), "The relationships among perceived quality, perceived risk and perceived product value". Journal of Product \& Brand Management, 13 (3), pp. 156-167.

Souza, P. N. P. (2009), "A revolução da EaD". Agitação, XV (89).

Stefano, N. M. (2013), "Uso da análise fatorial para avaliar a qualidade dos serviços". Iberoamerican Journal of Project Management (IJoPM), 4 (2), pp. 1-15. 


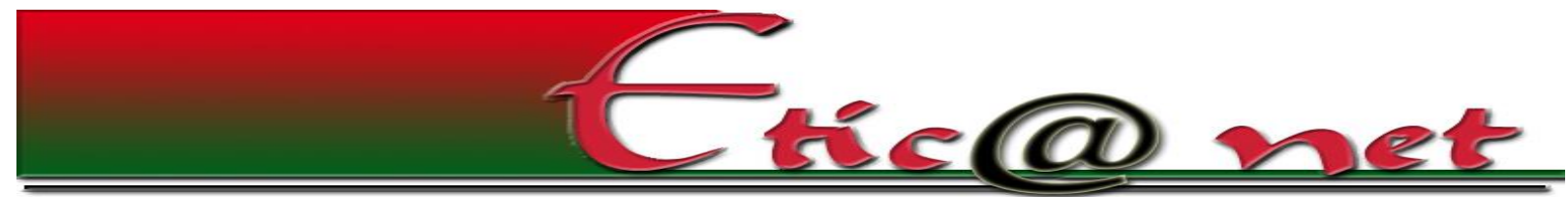

Revista científica electrónica de Educación y Comunicación en la Sociedad del Conocimiento Publicación en línea (Semestral) Granada (España) Época II Vol. 20 (2) Julio-Diciembre de 2020 ISSN: 1695-324X

Stefano, N. M. y Casarotto Filho, N. (2013), "Gestão do conhecimento e modelo SECI (Socialização-Externalização-Combinação-Internalização): na perspectiva do e-learning". Iberoamerican Journal of Project Management (IJoPM), 4 (1), p. 1-19.

Swart, J. y Kinnie, N. (2007), "Simultaneity of learning orientations in a marketing agency". Management Learning, 38 (3), pp. 337-357.

Thoms, B. y Eryilmaz, E. (2014), "How media choice affects learner interactions in distance learning clases". Computers \& Education, 75 (June), pp. 112126.

Tobías, M. A. y Fuentes, J. A. (2019). Open Educational Resources and MOOC: the digital literacy of English as a foreign language. Espacios, 40 (19).

URL:

https://www.revistaespacios.com/a19v40n19/a19v40n19p14.pdf

Tobías, M. A.; Fuentes, J. A.; Duarte, M. C. y Luiz, A. (2016). Los cursos online masivos abiertos $-\mathrm{MOOC}$ como estrategia de marketing en la Universidad. Etic@net, Revista científica electrónica de Educación y Comunicación en la Sociedad del Conocimiento, 16 (2), 349-370.

Varol, M. (2011), "Assessment of heavy metal contamination in sediments of the Tigris River (Turkey) using pollution indices and multivariate statistical techniques". Journal of Hazardous Materials, 195, pp. 355-364.

Wang, F. Y. - Carley, K. M. - Zeng, D. y Mao, W. (2007), "Social computing: From social informatics to social intelligence". Intelligent Systems, IEEE, 22 (2), pp. 79-83.

Wang, T-H. (2014), "Developing an assessment-centered e-Learning system for improving student learning effectiveness". Computers \& Education, 73, pp. 189-203.

Wild, R. H. - Griggs, K. A. y Downing T. (2002), "A framework for e-learning as a tool for knowledge management". Industrial Management \& Data Systems, 102 (7), pp. 371-380.

Yilmaz, Y. (2012), "Knowledge management in e-learning practices". The Turkish Online Journal of Educational Technology (TOJET), 11 (2), pp. 150-155. 